UNIVERSIDADE DE SÃO PAULO

FACULDADE DE ECONOMIA, ADMINISTRAÇÃO E CONTABILIDADE DEPARTAMENTO DE ECONOMIA PROGRAMA DE PÓS GRADUAÇÃO EM ECONOMIA

\title{
Previsibilidade do Mercado de Debêntures no Nível da Firma
}

Luís Menon José

Orientador: Prof. Dr. Alan De Genaro

São Paulo - Brasil 
Prof. Dr. Vahan Agopyan

Reitor da Universidade de São Paulo

Prof. Dr. Fábio Frezatti

Diretor da Faculdade de Economia, Administração e Contabilidade

Prof. Dr. José Carlos de Souza Santos

Chefe do Departamento de Economia

Prof. Dr. Ariaster Baumgratz Chimeli

Coordenador do Programa de Pós-Graduação em Economia 


\section{LUIS MENON JOSE}

\section{Previsibilidade do Mercado de Debêntures no Nível da Firma}

Dissertação apresentada ao Programa de Pós-Graduação em Economia do Departamento de Economia da Faculdade de Economia, Administração e Contabilidade da Universidade de São Paulo como requisito parcial para a obtenção do título de Mestre em Ciências.

Orientador:Prof. Dr. Alan De Genaro

Versão Corrigida

São Paulo - Brasil 


\section{FICHA CATALOGRÁFICA}

Elaborada por Rafael Mieli Rodrigues - CRB-8/7286

Seção de Processamento Técnico do SBD/FEA/USP

Menon Jose, Luis

Previsibilidade do Mercado de Debêntures no Nível da Firma / Luis Menon - São Paulo, 2019.

$42 \mathrm{p}$.

Dissertação (Mestrado) - Universidade de São Paulo, 2019.

Orientador: Alan De Genaro

1. Debêntures. 2. Renda fixa. 3. Liquidez. 4. Regressão Pooled. I. Universidade de São Paulo. Faculdade de Economia, Administração e Contabilidade. II. Título. 


\section{Agradecimentos}

À minha família. Principalmente à minha mãe Márcia, que me aguentou até nos dias de mau humor; à meu pai Artur, que sempre se preocupou com o andamento do mestrado; e ao meu irmão, interessado em entender um pouco do que eu aprendia.

Aos meus amigos do mestrado: Ahmad, Bernardo, Clara, Dornelas, Fabinho, Felipe, Joãzinho e Vinicius, que estiveram presentes em muitos momentos de estudo e sofrimento. Sem o apoio deles eu provavelmente teria desistido.

Aos meus amigos economistas (Kaian, Mauz, Rob e Samanta ) ,que tiveram paciência de me escutar muitas horas sobre este trabalho, além de contribuírem com diversas sugestões e correções.

Ao Nefin, que proporcionou infraestrutura e base de dados essenciais para conclusão desse trabalho. Também ao Eduardo Astorino e, especialmente, ao Elias, que sempre tiverem paciência para me ajudar a programar.

Ao meu orientador, Alan de Genaro. Provavelmente, uma das minhas melhores escolhas tenha sido convidá-lo a me orientar. Me ajudou muito na construção dessa tese e sempre esteve presente durante todo o processo de pesquisa.

Aos professores José Carlos e Antonio Gledson, pelas contribuições para este trabalho na avaliação de progresso.

À Fundação Instituto de Pesquisas Econômicas (FIPE) e Coordenação de Aperfeiçoamento de Pessoal de Nível Superior - Brasil (CAPES). pelo apoio financeiro. ${ }^{1}$

1 "O presente trabalho foi realizado com apoio da Coordenação de Aperfeiçoamento de Pessoal de Nível Superior - Brasil (CAPES) - Código de Financiamento 001 



\section{Resumo}

Esta dissertação analisa o mercado secundário de debêntures brasileiro, em particular, como ele se relaciona com o mercado de títulos públicos e o acionário. Foi construída uma base de dados que cruza informações de debêntures e ações no nível da firma, assim como títulos públicos pelo vencimento, totalizando 2024 observações mensais entre 2012 e 2018 . Os resultados mostram que a variação do yield da debênture pode ser explicada por: (I) variação do yield do título público; (II) retorno defasado da ação, sugerindo que existe um fluxo de informação do mercado acionário para mercado de títulos de renda fixa privados; e (III) a partir de 2018 com aumento do número de negócios, o retorno defasado da ação deixa de ter poder explicativo e, em seu lugar, o retorno contemporâneo passa a ser significativo, assim como outras variáveis do mercado tais quais o retorno do Índice Bovespa e os índices de volatilidade. Isso sugere que o mercado de debêntures se tornou mais dinâmico, incorporando mais rápido novas informações.

Palavras-chave: Debêntures. Renda fixa. Liquidez. Regressão Agrupada. 


\section{Abstract}

This project analyzes the secondary market of Brazilian corporate bonds, and how it relates to the bond market and the stock market. I built a database that crosses information from corporate bonds with stocks at the firm level as well as public bonds by maturity, totaling 2024 monthly observations between 2012 and 2018. The results show that the variation of the yield of the corporate bond can be explained by: (I) variation of the yield of the public bond; (II) for the lagged return of the stock, suggesting that there is a flow of information from the stock market to the bond market; and (iii) since 2018, with an increase in the number of trades, the lagged return loses its explanatory power. Instead, the contemporaneous return becomes significant, as well as other market variables such as the return of Bovespa index and the volatility indexes. This indicates that the corporate bond market became more dynamic, reacting to new information faster.

Keywords: corporate bonds. Fixed income. Liquidity. Pooled Regression. 


\section{Sumário}

INTRODUÇÃo $\ldots \ldots \ldots \ldots \ldots \ldots \ldots \ldots$

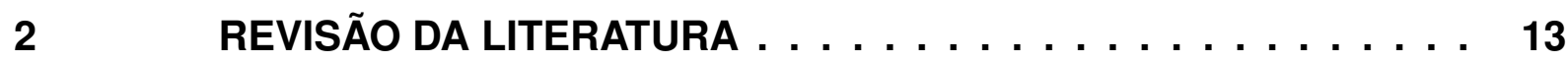

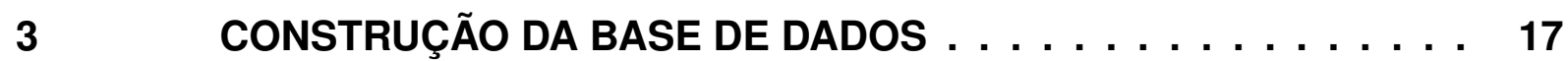

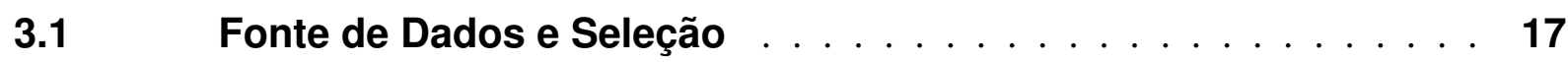

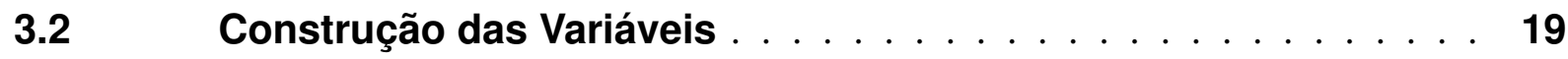

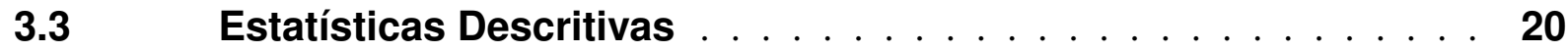

4 MODELO ECONOMÉTRICO $\ldots \ldots \ldots \ldots \ldots \ldots \ldots$

$5 \quad$ RESULTADOS . . . . . . . . . . . . 23

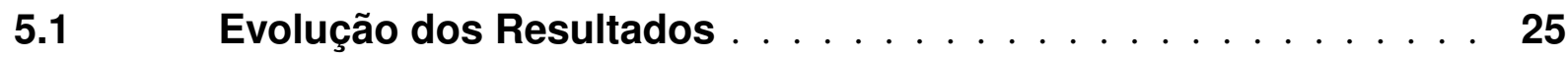

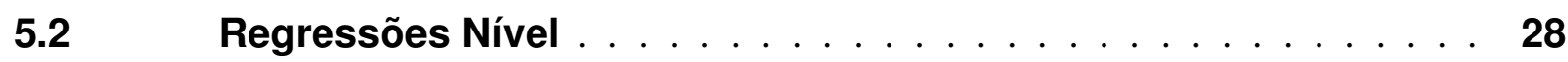

$5.3 \quad$ Robustez . . . . . . . . . . . . . . . . . . . . . . . . 29

$6 \quad$ CONCLUSÃo $\ldots \ldots \ldots \ldots \ldots \ldots \ldots \ldots \ldots \ldots \ldots$

$7 \quad$ APÊNDICE $\ldots \ldots \ldots \ldots \ldots \ldots \ldots \ldots \ldots \ldots \ldots$

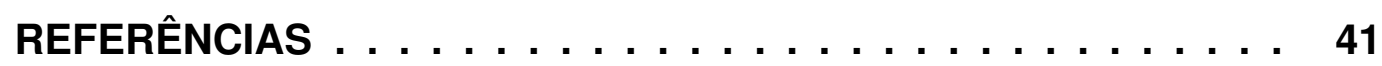





\section{Introdução}

O mercado de crédito brasileiro é ainda bastante incipiente e apresenta grande potencial de crescimento. Segundo dados do Bank for International Settlements (BID) a proporção de crédito privado para empresas do setor não financeiro, em relação ao PIB, foi de apenas $41 \%$ em 2017. Em outros países, como o Chile, este mesmo índice foi superior a 90\%. A tabela abaixo também revela que houve uma recente tendência de queda nesta razão, no Brasil, que retornou ao mesmo nível observado em 2012.

Tabela 1: Crédito para empresas do setor não financeiro em relação ao PIB

\begin{tabular}{|l|l|l|l|l|l|l|l|}
\cline { 2 - 7 } \multicolumn{1}{c|}{ Ano } & 2011 & 2012 & 2013 & 2014 & 2015 & 2016 & 2017 \\
\hline Brasil & $38 \%$ & $41 \%$ & $42 \%$ & $44 \%$ & $49 \%$ & $43 \%$ & $41 \%$ \\
\hline Chile & $76 \%$ & $81 \%$ & $87 \%$ & $96 \%$ & $105 \%$ & $101 \%$ & $95 \%$ \\
\hline Colombia & $30 \%$ & $29 \%$ & $32 \%$ & $36 \%$ & $41 \%$ & $38 \%$ & $35 \%$ \\
\hline Mexico & $18 \%$ & $18 \%$ & $21 \%$ & $22 \%$ & $25 \%$ & $27 \%$ & $27 \%$ \\
\hline G20 & $80 \%$ & $84 \%$ & $87 \%$ & $85 \%$ & $91 \%$ & $91 \%$ & $96 \%$ \\
\hline Mercados Emergentes & $71 \%$ & $76 \%$ & $82 \%$ & $88 \%$ & $92 \%$ & $93 \%$ & $92 \%$ \\
\hline Todos Países com dados reportados & $79 \%$ & $82 \%$ & $85 \%$ & $88 \%$ & $91 \%$ & $92 \%$ & $92 \%$ \\
\hline
\end{tabular}

Fonte: BIS, elaboração própria

O crédito bancário continua sendo a principal fonte de financiamento das empresas. Na figura 1, vemos que, apesar da menor importância do crédito direcionado via BNDES, o crédito, de maneira geral, continua sendo uma expressiva fonte de recursos para as empresas. Vale notar que a menor participação do crédito direcionado deve-se principalmente às mudanças de política do BNDES, tópico considerado em Horta et al. (2018). Este cenário também foi acompanhado de um crescimento do mercado de capitais no Brasil, que quase dobrou de importância durante o período observado: saindo de $15 \%$ para $25,3 \%$ (7,7\% do PIB) do exigível financeiro consolidado das empresas. 
Figura 1: Composição do exigível financeiro consolidado das empresas não financeiras brasileiras

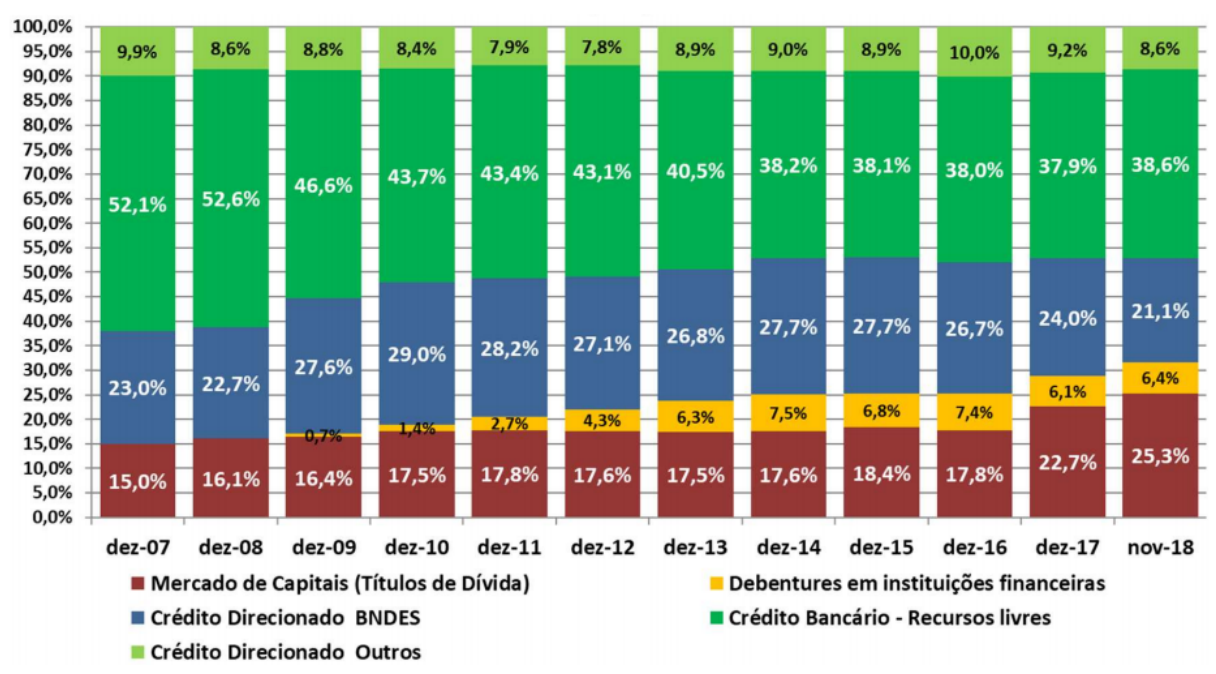

Fonte:Cemec

Atualmente, o principal ativo de renda fixa no Brasil são as debêntures: títulos de dívida que dão direito de crédito ao investidor. Nesta modalidade financeira o investidor recebe uma remuneração periódica (juros) e um valor no vencimento do título (principal). Este tipo de papel representou $62 \%$ do total de emissões do mercado de capitais em 2018 e seu volume vem crescendo constante nos últimos anos. Em 2018, o volume total de operações somou $\mathrm{R} \$ 139,6$ bilhões, que representou um aumento de $45 \%$ em relação ao volume observado no ano anterior, totalizando 303 operações.

Figura 2: Emissões Domésticas - Renda Fixa, Renda Variável e Híbridos Volume (R\$ milhões) 250.000

200.000

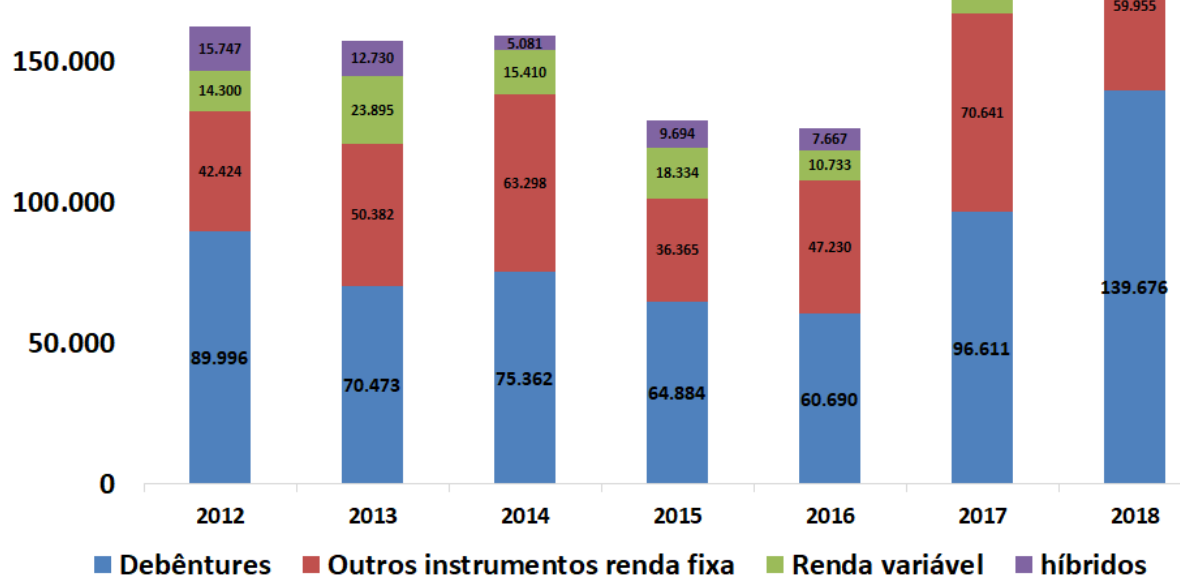

Fonte:Ambima, elaboração própria 
Este trabalho estuda o comportamento do mercado secundário de debêntures, que vem crescendo exponencialmente como pode-se observar na Figura 3. Em 2012, registrou-se apenas 7.034 negócios nesse mercado, enquanto que, seis anos depois, em 2018, houve 191.731 negócios registrados, equivalente a R \$52,9 bilhões. Esse volume de negócios, ainda que aparentemente grande, é diminuto quando comparado com o mercado de outros países: no mesmo período, o mercado de corporate bonds americano movimentou em média U\$34,1 bilhões por dia, segundo dados da Financial Industry Regulatory Authority (FINRA). Mais especificamente, esta dissertação analisa quais os fatores que explicam a variação no yield das debêntures. Para este fim, criou-se uma base de dados inédita, unificando informações de debêntures, títulos públicos e ações brasileiras entre 2012 e 2018. Os dados são organizados em forma de painel e a análise é feita usando um modelo de regressão empilhada, com os devidos controles para corrigir a estimativa dos erros-padrão considerando efeitos de autocorrelação e heterocedasticidade.

Figura 3: Número de negócios no mercado secundário

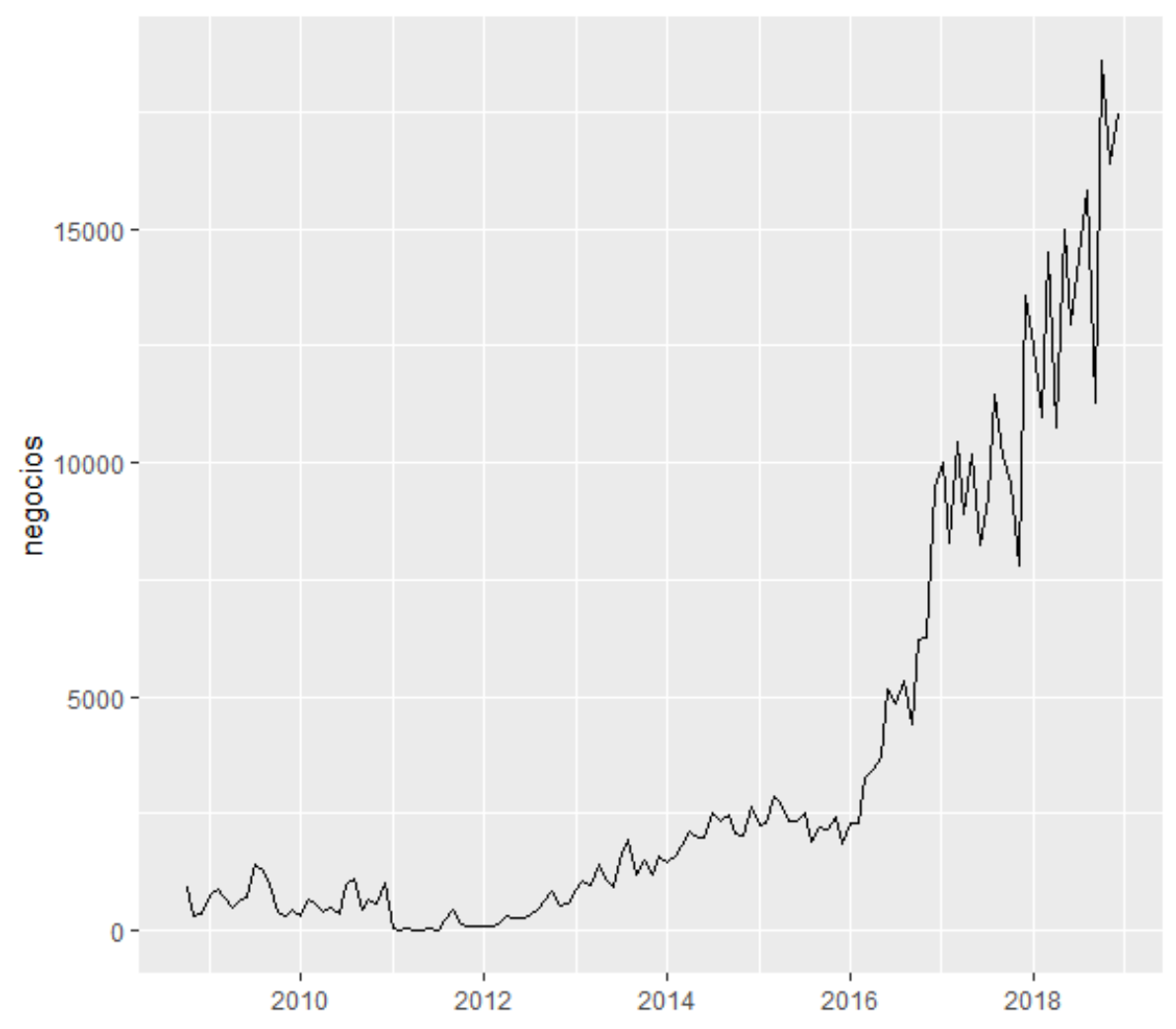

Fonte:Ambima , elaboração própria

Os resultados indicam que houve uma significativa mudança no mercado secundário de debêntures no período analisado. Entre 2012 e 2017 notamos que a variação do yield da debênture pode ser explicada pela variação na taxa de juros do título público e também pelo retorno defasado da respectiva ação. Esta última relação sugere que possa existir um fluxo de informações do mercado acionário para o mercado de títulos de renda fixa privados. A partir de 2018, há um aumento no volume de negócios. O comportamento do título público continua sendo uma 
variável relevante para explicar as variações no yield da debênture; contudo, o retorno defasado da ação deixa de ter poder explicativo: em seu lugar, o retorno contemporâneo da ação passar a ser estatisticamente significante. $\mathrm{O}$ mesmo pode ser observado usando outras variáveis do mercado tais quais o retorno do Índice Bovespa e índices de volatilidade, sugerindo que o mercado de debêntures está mais dinâmico, reagindo mais rapidamente às mudanças. Este artigo contribui para a literatura brasileira de finanças por ser um dos primeiros a estudar as variáveis que impactam a rentabilidade das debêntures no mercado secundário. Especificamente, investiga-se a relação deste mercado com o de títulos públicos e com o mercado acionário.

O restante do trabalho está dividido da seguinte forma: o capítulo 2 apresenta uma revisão da literatura de debêntures, discutindo os principais trabalhos que trataram desse tema, destacando os resultados encontrados por seus autores; o capítulo 3 descreve a base de dados que foi montada para o presente trabalho, além de apresentar as variáveis que serão utilizadas no modelo econométrico; o capítulo 4 descreve em maior detalhe o modelo econométrico; o capítulo 5 discute e interpreta os resultados do modelo econométrico; o capítulo 6 conclui o trabalho, resumindo sua contribuição; por fim, o capítulo 7 contém o apêndice onde são apresentadas os resultados das estimações de formulações alternativas do modelo econométrico. 


\section{Revisão da Literatura}

As debêntures são um tema recorrente na literatura econômica. A maioria dos trabalhos, que investiga este tema, busca explicar o nível do spread deste tipo de papel. Já a variação do spread é menos frequentemente abordada devido às dificuldades em encontrar bases de dados adequadas para estudar este assunto. Isto acontece pois, em geral, este tipo de papel é negociado no mercado de balcão. $\mathrm{O}$ estudo seminal acerca da precificação de debêntures, chamadas no Estados Unidos de corporate bonds, é de Merton (1974). Este trabalho propõe um modelo estrutural em que o prêmio de risco é função da razão do valor presente dos fluxos de caixa futuros do emissor e a volatilidade das suas operações. Uma parte bastante relevante desta literatura investiga a relação entre ações e debêntures de forma agregada (índices). Este é o caso de Campbell (1987) e Campbell e Ammer (1993). Já os trabalhos de Kawaller, Koch e Koch (1987) utilizam os retornos agregados lead-lag de outros tipos de ativos com o intuito de determinar a direção do fluxo de informações entre os mercados de ações e de debêntures.

Alguns estudos sugerem que os retornos e o spread de títulos emitidos por empresas norte-americanas podem apresentar uma co-variação. Um trabalho notável que segue esta direção é o de Fama e French (1993). Os autores documentam fatores de risco comum, como a taxa de juros e o risco de inadimplência, que podem gerar um comovimento entre ações e debêntures. Um estudo posterior, de King e Khang (2005), contudo, mostra que, controladas as variáveis relacionadas à inadimplência, os fatores de risco do mercado acionário têm um poder explicativo muito limitado.

O trabalho de Elton et al. (2001) compara a diferença entre o yield de títulos públicos e corporate bonds, decompondo o spread em três fatores: (I) na probabilidade de default; (II) nas diferenças das formas de tributação dos papéis; (III) e no prêmio por carregar um maior risco sistêmico. O trabalho conclui que este último fator é o mais importante. Para o título com vencimento em 10 anos, $39 \%$ do spread pode ser explicado pelo risco sistêmico.

Mais recentemente, Schaefer e Strebulaev (2008) concluem que o preço dos títulos corporativos do mercado americano pode ser explicado pelos juros do Tesouro dos títulos públicos, pelo índice de volatilidade implícita, assim como pelo retorno do mercado acionário, representado pelo SP500 (índice composto pelas quinhentos principais ações cotadas nas bolsas de NYSE e NASDAQ).

Há também estudos que exploram a correlação entre ações e debêntures no nível da firma. Neste sentido, pode-se destacar o trabalho de Kwan (1996) cuja análise baseia-se em regressões da variação do rendimento dos títulos contra o retorno das ações lead, lag e con- 
temporânea. Utilizando dados semanais de 1986 até 1990 do mercado americano, Kwan (1996) argumenta que novas informações nas firmas refletem-se primeiro no mercado acionário e, posteriormente, no mercado de debêntures. Um estudo similar, usando dados do mercado canadense, foi realizado por Cao, Galvani e Gubellini (2017). Usando dados no nível das firmas, os autores concluem que existe uma relação significativa entre as variações no yield das debêntures e o retorno das ações. Esta relação se dá não somente de forma contemporânea, mas também de forma defasada, sugerindo que pode haver um fluxo de informações relevantes do mercado ações para o mercado de títulos de renda fixa privada.

Outro aspecto comumente investigado nesta literatura é a influência da liquidez no mercado de corporate bonds. O trabalho de Lin, Wang e Wu (2011), usando dados do mercado americano, conclui que debêntures menos líquidas pagam prêmios de risco maiores. Por outro lado, uma melhora na liquidez das debêntures reduz significativamente o yield do papel. Os autores também concluem que a volatilidade das ações da empresa afeta apenas a variação do spread de títulos não classificados com grau de rating especulativos.

Não há estudos que relacionem os mercados de ações e de debêntures brasileiros: há apenas trabalhos que analisam exclusivamente o mercado de debêntures. Primeiro, pode-se destacar Sheng e Saito (2005), que estuda os determinantes do spread da taxa de juros das debêntures, notando os efeitos da classificação de rating na emissão de debêntures no Brasil entre 1999 e 2001 . O estudo dos autores conclui que quanto melhor for o rating, menor será o spread, independentemente do país de origem da agência de risco que emitir o rating.

Gonçalves e Sheng (2010) focam seu trabalho na liquidez do mercado secundário. Analisando o período de 2004 a 2006, os autores consideram 4 variáveis de liquidez: o volume de emissão, a idade da emissão, o número de transações no dia e, finalmente, o spread de compra e venda. Os autores argumentam que o prêmio exigido pelos investidores, por aplicarem em papéis menos líquidos, varia de 8 a 30 pontos percentuais. Já Securato, Carrete e Junior (2006) testam um modelo binomial na formação de preços de títulos de dívida e de seus componentes adaptados à realidade brasileira.

Paula (2016) estuda os efeitos da implementação do sistema de Registro Único de Preços (REUNE). Neste sistema são registradas as negociações do mercado secundário de debêntures. Com essas informações, a Anbima (Associação Brasileira das Entidades dos Mercados Financeiros e de Capitais) divulga os preços praticados no mercado ao longo do dia. O trabalho conclui que a introdução do sistema aumentou a transparência e a liquidez do mercado secundário de debêntures.

Ao analisar o histórico regulatório do mercado de debêntures, faz-se necessário notar a criação da Instrução $n^{\circ} 476$ de 2009, que visou a desburocratizar o mercado, simplificando a forma de emitir novos papéis. Este tipo de emissão é uma oferta pública de esforço restrito, destinada apenas aos investidores qualificados e que não exige um registro prévio na Anbima, tampouco a publicação de um prospecto e uma classificação de crédito. Também vale destacar a 
criação da instrução CBM n ${ }^{\circ} 47$ e a Lei n ${ }^{\circ} 12.431$, de junho de 2011, que estabelece isenções tributárias para títulos ligados a projetos de infraestrutura. Carvalho (2019) explorou os impactos dessas mudanças regulatórias. Ele encontra evidência de que parte do crescimento do volume de debêntures depois da criação da Instrução $n^{0} 476$ pode ser explicado por uma substituição de operações de crédito bancário por emissões de debêntures, nas quais o banco garante a alocação dos títulos - inclusive adquirindo parte delas. Isto ocorre devido às vantagens fiscais contábeis de que gozam os bancos. 



\section{Construção da Base de Dados}

Nesta seção, descreve-se como foi construída a base de dados. Ela é dividida em três partes: (I) na primeira detalha-se as fontes das bases de dados e a forma como a amostra foi selecionada; (II) na parte seguinte explica-se como foi feita a construção das variáveis; (III) na última parte apresenta-se as estatísticas descritivas dos dados.

\subsection{Fonte de Dados e Seleção}

Os dados dos yields do mercado secundário das debêntures e dos títulos públicos são coletados pela Anbima (Associação Brasileira das Entidades dos Mercados Financeiro e de Capitais) junto aos principais dealers destes mercados. Segundo a Associação, os yields disponíveis correspondem "às taxas avaliadas pela instituição como preço justo de negócio para cada emissão, de acordo com os modelos individuais de precificação, independentemente de ter ocorrido negócio com o ativo". Como o mercado de debêntures, em especial, é pouco líquido, são retiradas da amostra observações de dias que não tiveram nenhum negócio, de tal forma que a taxa observada reflete movimentações de mercado, não apenas variações imateriais.

Do site www.debentures.com.br, mantido pela Anbima, coletou-se as informações do mercado secundário, relativas a quantidade de títulos, número de negócios, duration e preços mínimos e máximos das debêntures. O preço e volume de negócio das ações e dos títulos públicos são retirados do portal economatica. Desta mesma fonte também são retiradas informações cadastrais de todos os papéis, como o CNPJ da empresa, que permite o pareamento entre as ações e as debêntures, a data da emissão e de vencimento do ativo, o setor, o tipo de emissão e a sua remuneração.

Os dados diários do índice Ibovespa são retirados do IPEADATA. O NEFIN (Brazilian Center for Research in Financial Economics) é a fonte para a variável do índice de volatilidade do mercado acionário brasileiro, o Vol-Br, calculado a partir da metodologia apresentada em (ASTORINO et al., 2017). Já o VIX, medida de volatilidade do mercado americano calculada pela Chicago Board Options Exchange, é retirado do site do FRED.

Os três principais tipos de debêntures negociadas no Brasil são: (I) DI spread, em que o papel promete pagamento da taxa DI acrescida de um spread em pontos percentuais (ex. DI + $3 \%$ ); (II) DI percentual, em que a taxa referencial é um percentual do DI (ex. 106\% DI); e (III) IPCA spread, que paga a inflação apurada pelo IPCA acrescido de um prêmio (ex IPCA + 6\%).

Para este trabalho selecionou-se apenas os títulos IPCA spread. Estes títulos são os únicos que possibilitam utilização de títulos públicos como controle para variações dos juros da economia, permitindo separar a variação da taxa de juros das variações idiossincráticas de cada 
debênture. Foram retiradas da amostra papéis de empresa que não têm capital aberto em bolsa. No caso de empresas que tenham mais de um tipo de ação negociada em bolsa, optamos pelo papel com maior volume de negócios.

A amostra de debêntures utilizada após os filtros conta com 76 papéis de 35 empresas diferentes no período entre 2011 e 2018 (os dados de volume de negócio estão disponíveis apenas para esse período), totalizando 13.885 observações diárias. Como as observações não aparecem de forma regular, optou-se por agregar a base nas frequência mensal. 


\subsection{Construção das Variáveis}

Abaixo são listadas as variáveis e a forma como foram construídas.

Tabela 2: A tabela apresenta a definição das variáveis consideradas e as transformações realizadas nelas. Quando se falar de variação está-se implicitamente considerando a varição percentual, isto é, quando se falar de variação do yield da debênture quer-se dizer varição percentual no yield da debênture. Quando for utilizada variação simples isto será mencionado explicitamente.

\begin{tabular}{|c|c|c|}
\hline Variável & Definição & Construção \\
\hline Yield $_{j, t}$ & Juros pagos pela debênture & \\
\hline$T_{j, t}$ & Juros pagos pela NTN-B & $\begin{array}{l}\text { pareado com a debênture de } \\
\text { mesmo vencimento }\end{array}$ \\
\hline$\Delta$ Yield $_{j, t}$ & $\begin{array}{l}\text { variação percentual do yield } \\
\text { título }\end{array}$ & $\begin{array}{l}\Delta \text { Yield }_{j, t}=\left(\text { Yield }_{j, t}-\right. \\
\left.\text { Yield }_{j, t-1}\right) / \text { Yield }_{j, t-1}\end{array}$ \\
\hline Dif - Yield $_{j, t}$ & $\begin{array}{l}\text { variação simples do yield tí- } \\
\text { tulo }\end{array}$ & $\begin{array}{l}\text { Dif }- \text { Yield }_{j, t}=\left(\text { Yield }_{j, t}-\right. \\
\left.\text { Yield }_{j, t-1}\right)\end{array}$ \\
\hline$\Delta T_{i, j}$ & $\begin{array}{l}\text { Variação na taxa de juros da } \\
\text { NTN-B }\end{array}$ & $\Delta T_{j, t}=\left(T_{j, t}-T_{j, t-1}\right) / T_{j, t-1}$ \\
\hline$D i f-T_{i, j}$ & $\begin{array}{l}\text { Variação simples na taxa de } \\
\text { juros da NTN-B }\end{array}$ & Dif $-T_{j, t}=\left(T_{j, t}-T_{j, t-1}\right)$ \\
\hline$R_{j, t}$ & Retorno da ação no período & $\begin{array}{l}R_{j, t}=\ln \left(\text { Preco }_{j, t}\right)- \\
\ln \left(\text { Preco }_{j, t-1}\right)\end{array}$ \\
\hline $\operatorname{Rbov}_{t}$ & Retorno do ibovespa período & $\begin{array}{l}\text { Rbov }_{t}=\ln \left(\text { ibovespa }_{t}\right)- \\
\ln \left(\text { ibovespa }_{t-1}\right)\end{array}$ \\
\hline$V i x_{t}$ & $\begin{array}{l}\text { Volatilidade do mercado ame- } \\
\text { ricano }\end{array}$ & Ver (WHALEY, 1993) \\
\hline Volbr $_{t}$ & $\begin{array}{l}\text { Volatilidade do mercado bra- } \\
\text { sileiro }\end{array}$ & Ver (ASTORINO et al., 2017) \\
\hline Duration $_{j, t}$ & $\begin{array}{l}\text { Prazo médio no qual o deten- } \\
\text { tor recupera o investimento } \\
\text { feito }\end{array}$ & $\begin{array}{l}\text { Calculada pela Ambima se- } \\
\text { gundo manual de apressa- } \\
\text { mento de taxas e título }\end{array}$ \\
\hline$E w m a_{j, t}$ & $\begin{array}{l}\text { Media móvel exponencial da } \\
\text { volatilidade da ação }\end{array}$ & $\begin{array}{l}E w m a_{j, t}=\sigma_{j, t}^{2} * \lambda+(1-\lambda) * \\
\sigma_{j, t-1}^{2}\end{array}$ \\
\hline spread $_{j}, t$ & $\begin{array}{l}\text { Spread de compra e venda das } \\
\text { debêntures }\end{array}$ & taxa $a_{\text {compra }}-$ taxa $a_{\text {venda }}$ \\
\hline Estatal $_{j}$ & $\begin{array}{l}\text { Dummy que assume valor } 1 \\
\text { para empresa estatal }\end{array}$ & $\begin{array}{l}\text { Maior acionista da empresa } \\
\text { é o governo tabela (15) no } \\
\text { anexo }\end{array}$ \\
\hline
\end{tabular}




\subsection{Estatísticas Descritivas}

A Tabela 3 abaixo apresenta estatísticas que resumem o comportamento das variáveis selecionadas. Vale reforçar que as variáveis foram agregadas em frequência mensal. De imediato, destaca-se que o yield das debêntures selecionadas é de 5,99\%, com desvio padrão de 1,6\%. Já os títulos públicos tem uma média de 5,052\% com desvio de 1,279\%. Tal qual o esperado, os papéis de dívida do governo, por apresentarem um risco menor, têm taxas mais baixas, porém comparáveis, em relação às taxas das debêntures. A média dos retornos das ações é de $0,011 \%$, valor próximo ao retorno médio do IBOVESPA, que é $0,012 \%$. Podemos observar que cada papel tem, em média, 33,7 negócios por mês, enquanto que a mediana é de apenas 16 negócios, o que é explicado pelo elevado número de negócios em alguns dias específicos. Da amostra, $75 \%$ correspondem a observações de papéis emitidos via Instrução $n^{\circ} 476$, enquanto $38 \%$ das observações são de empresas estatais.

Tabela 3: Estatísticas descritivas (2012 a 2018). A tabela reporta estatísticas descritivas para as principais variáveis: yield e variação do yield das debêntures e da taxa de juros NTN-B, retornos da ação $\left(R_{j, t}\right)$ e do Ibovespa $\left(R b o v_{t}\right)$, índices de volatilidade dos mercados brasileiro (ivolbr) e americano (vix). A variáveis Estatal e Emissão 476 são as dummies descritas acima

\begin{tabular}{lcccccc}
\hline \hline \multicolumn{1}{c}{ Variáveis } & Obs. & Média & Desvio Padrão & Min. & Máx. & Mediana \\
\hline Yield $_{j, t}$ & 2103 & 5.99 & 1.66 & .25 & 18.65 & 5.64 \\
$\Delta$ Yield $_{j, t}$ & 2024 & -.01 & .11 & -2.24 & 2.86 & -.008 \\
$T_{j, t}$ & 2103 & 5.05 & 1.27 & -2.08 & 9.08 & 5.25 \\
$\Delta T_{i, j}$ & 2012 & -.01 & .10 & -1.58 & 1.04 & -.005 \\
Rbov $_{t}$ & 2024 & .012 & .069 & -.234 & .46 & .009 \\
$R_{j, t}$ & 2024 & .011 & .103 & -.636 & .883 & .005 \\
Duration & 2103 & 999.87 & 425.37 & 3 & 2188 & 992.97 \\
spread $_{j}, t$ & 2103 & .08 & .26 & -.25 & 11.98 & .07 \\
número de negócios & 2103 & 33.747 & 58.907 & 1 & 1057 & 16 \\
dias sem negocio & 2102 & 18.655 & 8.131 & 0 & 29 & 20 \\
Estatal & 2073 & .388 & .487 & 0 & 1 & 0 \\
emissão 476 & 2103 & .75 & .428 & 0 & 1 & 1 \\
ivolbr & 2103 & 22.97 & 4.16 & 13.22 & 42.27 & 22.45 \\
vix & 2103 & 15.03 & 4.69 & 9.22 & 42.36 & 13.53 \\
\hline
\end{tabular}




\section{Modelo Econométrico}

A metodologia econométrica do presente trabalho consiste em uma regressão da variação do yield da debênture, $\Delta Y$ ield $_{j, t}$, contra: a variação do yield do título público, $\Delta T_{j, t}$, o retorno futuro da ação, $R_{j, t+1}$, o retorno contemporâneo da ação, $R_{j, t}$, o retorno defasado da ação, $R_{j, t-1}$, e, finalmente, um conjunto de variáveis de controle, $C O N T_{j, t}$. Como controles foram incluídos: (i) o retorno do mesmo período do Ibovespa, para capturar possíveis choque da economia brasileira de forma agregada; (ii) uma dummy para debêntures que foram emitidas através da Instrução $n^{\circ} 476$, que regula emissões não direcionadas ao grande público; (iii) uma variável de volatilidade das ações da empresa; (iv) duas variáveis de volatilidade do mercado brasileiro e internacional; e (v) variáveis de liquidez.

Considerou-se o seguinte modelo linear, exposto abaixo, que foi inicialmente proposto por Kwan (1996), descrito abaixo:

$$
\Delta \text { Yield }_{j, t}=\beta_{0}+\beta_{1} \Delta T_{j, t}+\beta_{2} R_{j, t+1}+\beta_{3} R_{j, t}+\beta_{4} R_{j, t-1}+\gamma C O N T_{j, t}+e_{j, t}
$$

Como as debêntures são títulos de renda fixa, espera-se que sejam fortemente influenciadas por variações na taxa de juros livre de risco da economia. Neste sentido, o parâmetro $\beta_{1}$ deve ser positivo e significante. Caso o mercado de debêntures se ajuste de maneira instantânea, após a divulgação de novas informações, seria esperado que haja somente correlação contemporânea entre os retornos e a variação do yield das debêntures. Isto é, deveríamos observar $\beta_{2} \mathrm{e}$ $\beta_{4}$ iguais a zero. Se $\beta_{4}$ for diferente de zero, então há indício de que existe uma relação entre o yield das debêntures e o lag retorno da ação. Este resultado sugeriria que novas informações das empresas se refletem primeiro no preço das ações e, posteriormente, no mercado de debêntures, pois "agentes bem informados" optam pelo mercado de ações pela sua maior liquidez. Por outro lado, caso $\beta_{2}$ seja diferente de zero, então pode existir um fluxo de informações das firmas, que surge primeiro nas debêntures e depois afeta a variação do yield das ações. Assim, a variação do yield carregaria informações relevantes para o mercado futuro de ações.

No presente estudo são estimadas regressões pooled: desta forma é possível extrair um coeficiente médio entre as várias debêntures. Além disso, incorpora-se a matriz de covariância de Newey e West (1986), que permite abarcar efeitos de heterocedasticidade e autocorrelação na estimação dos erros padrão. Para a estimação utilizou-se o software Stata com o pacote "NEWEY2" de Roodman (2009).

Estimou-se, também, uma especificação alternativa da expressão ((4.1)) acima, seguindo Cao, Galvani e Gubellini (2017). Nesta formulação estima-se uma regressão da primeira diferença do yield da debênture, Dif - Yield $_{j, t}$, contra: a primeira diferença do yield do título 
público, Dif $-T_{i, j}$; o retorno futuro da ação $R_{j, t+1}$; o retorno defasado da ação, $R_{j, t-1}$; e o retorno contemporâneo da ação. Além dessas variáveis, novamente considera-se também um vetor de controles. A equação desta especificação alternativa segue abaixo:

$$
\text { Dif }- \text { Yield }_{j, t}=\beta_{0}+\beta_{1} D i f-T_{i, j}+\beta_{2} R_{j, t+1}+\beta_{3} R_{j, t}+\beta_{4} R_{j, t-1}+\gamma C O N T_{j, t}+e_{j, t}
$$

Vale ressaltar que não é apropriado utilizar o retorno das debêntures pois este valor reflete variações do fluxo de pagamentos de juros e amortizações, em que cada papel segue uma lógica própria, dificultando uma análise adequada.

Também foi estimado um modelo onde a variável dependente é o yield da debênture em nível, como apresentado na expressão ((4.3)) abaixo, contra o yield do título público e com as seguintes variáveis de controle: dummy para empresa estatal, dummy para emissão via instrução $\mathrm{n}^{\mathrm{o}}$ 476, liquidez de Amihud, dias sem negócio, spread de compra e venda e duration. O intuito desta formulação é entender se as variáveis independentes têm capacidade para explicar o nível do yield.

$$
\text { Yield }_{j, t}=\beta_{0}+\beta_{1} T_{i, j}++\gamma C O N T_{j, t}+e_{j, t}
$$




\section{Resultados}

O principal resultado da regressão, conforme a equação ((4.1)), é sumarizado na tabela 4. O período considerado foi de 2012 a 2018. Cada debênture foi pareada com a NTN-B de vencimento mais próximo, assim como o retorno contemporâneo, defasado e futuro da ação mais líquida da mesma firma. Em seguida, a amostra foi reunida empilhando as observações da série temporal das debêntures. A amostra total é composta de 1.860 observações.

Em cada coluna da tabela abaixo, considera-se diferentes controles anteriormente mencionados. Na primeira coluna, apresenta-se o resultado da estimação do modelo sem nenhum controle adicional, seguindo o modelo proposto em (). Na coluna seguinte, adiciona-se os controles relacionados com as variáveis de mercado: o retorno do Ibovespa e o índices Vol-br e VIX. Na terceira coluna insere-se as variáveis específicas da firma: a volatilidade da ação, conforme testado por Campbell e Taksler (2003), a dummy para as emissões da instrução $\mathrm{n}^{\circ} 476 \mathrm{e}$ a dummy para empresas estatais. A quarta coluna inclui proxies de liquidez: dias sem negócio, liquidez de Amihud e o spread de compra e venda utilizados por Gonçalves e Sheng (2010). Por fim, na última coluna, o modelo é estimado com todas as variáveis e com um efeito fixo para cada debênture. 
Tabela 4: Regressões empilhadas - variável dependente: variação do yield da debênture (2012 a 2018). A tabela apresenta os coeficientes estimados de especificações alternativas da equação (4.1). Na coluna 1 usa-se a variação do yield do título público, além dos retornos defasado, contemporâneo e futuro da ação $\left(R_{j, t-1}, R_{j, t}, R_{j, t+1}\right)$. Na coluna 2 adiciona-se variáveis de mercado: retorno corrente do Ibovespa $\left(R b o v_{t}\right)$ e índices de volatilidade $\left(V_{i x_{t}}, V_{o l b r}\right)$. Na coluna 3 considera-se adiciona-se dummies de firma (Estatal e emissão 476), além de um EWMA para a ação. Na coluna 4 considera-se efeitos de liquidez e na última coluna insere-se efeito fixo para cada firma, omitindo as dummies.

\begin{tabular}{|c|c|c|c|c|c|}
\hline Variáveis & $\begin{array}{c}1) \\
\text { Base } \\
\end{array}$ & $\begin{array}{c}(2) \\
\text { Mercado }\end{array}$ & $\begin{array}{c}\text { (3) } \\
\text { Mercado-empresa }\end{array}$ & $\begin{array}{c}\text { (4) } \\
\text { Liquidez }\end{array}$ & $\begin{array}{l}(5) \\
\mathrm{EF}\end{array}$ \\
\hline$\Delta T_{i, t}$ & $\begin{array}{r}0.448 * * * \\
(0.0728)\end{array}$ & $\begin{array}{c}0.413 * * * \\
(0.0736)\end{array}$ & $\begin{array}{c}0.405^{* * * *} \\
(0.0726)\end{array}$ & $\begin{array}{c}0.404 * * * \\
(0.0731)\end{array}$ & $\begin{array}{l}0.412 * * * \\
(0.0693)\end{array}$ \\
\hline$R_{j, t+1}$ & $\begin{array}{l}-0.00979 \\
(0.0127)\end{array}$ & $\begin{array}{l}-0.0159 \\
(0.0124)\end{array}$ & $\begin{array}{l}-0.0184 \\
(0.0120)\end{array}$ & $\begin{array}{l}-0.0167 \\
(0.0122)\end{array}$ & $\begin{array}{r}-0.00651 \\
(0.0108)\end{array}$ \\
\hline$R_{j, t}$ & $\begin{array}{c}-0.0603 * * \\
(0.0302)\end{array}$ & $\begin{array}{l}-0.00392 \\
(0.0207)\end{array}$ & $\begin{array}{l}-0.00555 \\
(0.0204)\end{array}$ & $\begin{array}{l}-0.00563 \\
(0.0205)\end{array}$ & $\begin{array}{l}0.00364 \\
(0.0244)\end{array}$ \\
\hline$R_{j, t-1}$ & $\begin{array}{c}-0.0498 * * * \\
(0.0137)\end{array}$ & $\begin{array}{c}-0.0484 * * * \\
(0.0149)\end{array}$ & $\begin{array}{c}-0.0522 * * * \\
(0.0162)\end{array}$ & $\begin{array}{c}-0.0496 * * * \\
(0.0165)\end{array}$ & $\begin{array}{c}-0.0422 * * * \\
(0.0140)\end{array}$ \\
\hline $\operatorname{Rbov}_{t}$ & & $\begin{array}{c}-0.176 * * * \\
(0.0490)\end{array}$ & $\begin{array}{c}-0.187 * * * \\
(0.0470)\end{array}$ & $\begin{array}{c}-0.179 * * * \\
(0.0489)\end{array}$ & $\begin{array}{c}-0.183 * * * \\
(0.0372)\end{array}$ \\
\hline$V i x_{t}$ & & $\begin{array}{c}-0.000696 * \\
(0.000422)\end{array}$ & $\begin{array}{c}-0.000925 * * \\
(0.000371)\end{array}$ & $\begin{array}{c}-0.000932 * * \\
(0.000372)\end{array}$ & $\begin{array}{c}-0.000874 * * \\
(0.000359)\end{array}$ \\
\hline Volbr $_{t}$ & & $\begin{array}{c}-0.00130 * * * \\
(0.000323)\end{array}$ & $\begin{array}{c}-0.00131 * * * \\
(0.000318)\end{array}$ & $\begin{array}{c}-0.00137 * * * \\
(0.000308)\end{array}$ & $\begin{array}{c}0.00144 * * * \\
(0.000290)\end{array}$ \\
\hline$E w m a_{j, t}$ & & & $\begin{array}{c}0.0965 \\
(0.0871)\end{array}$ & $\begin{array}{c}0.125 \\
(0.109)\end{array}$ & $\begin{array}{l}0.548 * \\
(0.283)\end{array}$ \\
\hline Estatal & & & $\begin{array}{c}0.00387 \\
(0.00264)\end{array}$ & $\begin{array}{c}0.00354 \\
(0.00274)\end{array}$ & \\
\hline emissão-476 & & & $\begin{array}{l}-0.00328 \\
(0.00354)\end{array}$ & $\begin{array}{l}-0.00218 \\
(0.00335)\end{array}$ & \\
\hline Efeito Fixo & Não & Não & Não & Não & Sim \\
\hline Controles de liquidez & Não & Não & Não & Sim & Sim \\
\hline Observações & 1,860 & 1,860 & 1,838 & 1,838 & 1,860 \\
\hline $\mathrm{R}$-squared & 0.445 & 0.469 & 0.500 & 0.507 & 0.517 \\
\hline
\end{tabular}

Os resultados mostram que, independentemente da especificação do modelo, o coeficiente relacionado ao título público é sempre significativo a $1 \%$, apresentando valores entre 0,412 e 0,448 . Ou seja, um aumento de $1 \%$ no yield do título público de mesmo vencimento aumenta em $0,4 \%$ o yield da debênture. Este resultado é esperado, pois o título público é o papel de menor risco da economia, logo sua flutuação baliza a variação dos demais títulos de renda fixa.

O coeficiente correspondente ao retorno do período seguinte das ações da empresa não é significativo em qualquer uma das diferentes especificações propostas. Isto sugere que não há fluxo de informações partindo do mercado de títulos corporativos para o mercado acionário. O retorno contemporâneo das ações é significativo apenas no primeiro modelo, que omite as variáveis de controle. Ao incluir variáveis de mercado, o retorno contemporâneo perde significância, já que, segundo a teoria econômica, deve existir uma correlação entre o retorno da ação e o retorno do mercado.

Já o retorno defasado das ações é significativo com coeficientes estimados entre $-0,06$ 
e - 0,04 . O valor negativo, conforme explicado na seção anterior, sugere que informações que afetam positivamente o valor das ações diminuem a probabilidade de default da debênture, reduzindo seu yield. Este resultado sugere que o retorno da ação individual pode ter um poder de previsão sobre a debênture correspondente.

Nota-se que o coeficiente relacionado com a instrução $n^{0} 476$ não é significativo nas duas especificações que consideram esta variável. Assim, o tipo de emissão parece não explicar a variação do yield da debênture. Este resultado pode ser influenciado pelos critérios de seleção da amostra, pois foram incluídas apenas empresas de capital aberto que alternativamente poderiam ter feito a emissão do papel via a Instrução $n^{0} 400$.

\subsection{Evolução dos Resultados}

Uma segunda análise proposta por este trabalho é entender se o resultado encontrado acima é dependente do período considerado na amostra. A tabela 5 abaixo mostra o número de observações da amostra em cada ano contemplado. Nota-se que 32\% dos dados estão concentrados no de 2018. Por este motivo, separou-se a amostra em dois períodos: um primeiro recorte, com início em 2012 e fim em 2017, e um segundo, que considera apenas o ano de 2018. Os resultados das regressões para a primeira subamostra são apresentados na tabela 6 , e os da segunda subamostra são apresentados na tabela 7.

Tabela 5: Número de observações da amostra.

\begin{tabular}{|c|c|}
\hline Ano & observações \\
\hline 2012 & 27 \\
\hline 2013 & 112 \\
\hline 2014 & 167 \\
\hline 2015 & 230 \\
\hline 2016 & 345 \\
\hline 2017 & 496 \\
\hline 2018 & 671 \\
\hline
\end{tabular}

Ao comparar-se o resultado das duas tabelas pode-se destacar alguns pontos. O coeficiente da variação do título público é significante a $1 \%$ em ambas as subamostras analisadas. Esta relação, portanto, não mudou ao longo dos anos. Além disso, o coeficiente do retorno defasado da ação é significativo para as estimações que consideram o período entre 2012 e 2017, porém deixa de ser relevante quando se considera somente o ano de 2018. Neste último caso, ao invés do retorno defasado, observa-se que o retorno contemporâneo passa a ser significativo. Isto indica que o aumento do número de negócios aumenta a eficiência do mercado; novas informações que antes demoravam para afetar o mercado de títulos corporativos, agora são incorporadas mais rapidamente. Por fim, pode-se observar que as variáveis de mercado têm maior poder ex- 
plicativo nos modelos de 2018, corroborando a hipótese de que o mercado de debêntures tem se tornado mais eficiente ao longo dos anos.

Tabela 6: Regressões empilhadas - variável dependente: variação do yield da debênture (2012 a 2017). A tabela apresenta os coeficientes estimados de especificações alternativas da equação (4.1). Na coluna 1 usa-se a variação do yield do título público, além dos retornos defasado, contemporâneo e futuro da ação $\left(R_{j, t-1}, R_{j, t}, R_{j, t+1}\right)$. Na coluna 2 adiciona-se variáveis de mercado: retorno corrente do Ibovespa $\left(R_{b o v}\right)$ e índices de volatilidade $\left(V i x_{t}, V o l b r_{t}\right)$. Na coluna 3 considera-se adiciona-se dummies de firma (Estatal e emissão 476), além de um EWMA para a ação. Na coluna 4 considera-se efeitos de liquidez e na última coluna insere-se efeito fixo para cada firma, omitindo as dummies.

\begin{tabular}{|c|c|c|c|c|c|}
\hline Variáveis & $\begin{array}{c}(1) \\
\text { Base }\end{array}$ & $\begin{array}{c}(2) \\
\text { Mercado }\end{array}$ & $\begin{array}{c}(3) \\
\text { Mercado-empresa }\end{array}$ & $\begin{array}{c}\text { (4) } \\
\text { Liquidez }\end{array}$ & $\begin{array}{l}(5) \\
\mathrm{EF}\end{array}$ \\
\hline$\Delta T_{i, t}$ & $\begin{array}{c}0.447 * * * \\
(0.0812)\end{array}$ & $\begin{array}{c}0.425 * * * \\
(0.0807)\end{array}$ & $\begin{array}{c}0.413 * * * \\
(0.0801)\end{array}$ & $\begin{array}{c}0.459 * * * \\
(0.0778)\end{array}$ & $\begin{array}{c}0.467 * * * \\
(0.0838)\end{array}$ \\
\hline$R_{j, t+1}$ & $\begin{array}{c}-5.09 \mathrm{e}-05 \\
(0.0113)\end{array}$ & $\begin{array}{l}-0.0106 \\
(0.0115)\end{array}$ & $\begin{array}{l}-0.0123 \\
(0.0115)\end{array}$ & $\begin{array}{l}-0.00894 \\
(0.0127)\end{array}$ & $\begin{array}{l}-0.00271 \\
(0.0102)\end{array}$ \\
\hline$R_{j, t}$ & $\begin{array}{l}-0.00683 \\
(0.0190)\end{array}$ & $\begin{array}{c}0.0227 \\
(0.0157)\end{array}$ & $\begin{array}{c}0.0183 \\
(0.0156)\end{array}$ & $\begin{array}{c}0.0149 \\
(0.0168)\end{array}$ & $\begin{array}{c}0.0215 \\
(0.0161)\end{array}$ \\
\hline$R_{j, t-1}$ & $\begin{array}{c}-0.0664 * * * \\
(0.0151)\end{array}$ & $\begin{array}{c}-0.0654 * * * \\
(0.0160)\end{array}$ & $\begin{array}{c}-0.0687 * * * \\
(0.0190)\end{array}$ & $\begin{array}{c}-0.0652 * * * \\
(0.0201)\end{array}$ & $\begin{array}{c}-0.0545 * * * \\
(0.0154)\end{array}$ \\
\hline $\operatorname{Rbov}_{t}$ & & $\begin{array}{c}-0.0756 * * \\
(0.0371)\end{array}$ & $\begin{array}{c}-0.0822 * * \\
(0.0350)\end{array}$ & $\begin{array}{c}-0.0748 * * \\
(0.0365)\end{array}$ & $\begin{array}{c}-0.0835 * * \\
(0.0349)\end{array}$ \\
\hline$V i x_{t}$ & & $\begin{array}{l}-0.000345 \\
(0.000357)\end{array}$ & $\begin{array}{l}-0.000541 \\
(0.000412)\end{array}$ & $\begin{array}{l}-0.000632 \\
(0.000471)\end{array}$ & $\begin{array}{l}-0.000480 \\
(0.000420)\end{array}$ \\
\hline Volbr $_{t}$ & & $\begin{array}{c}-0.00231 * * * \\
(0.000338)\end{array}$ & $\begin{array}{c}-0.00237 * * * \\
(0.000349)\end{array}$ & $\begin{array}{c}-0.00250 * * * \\
(0.000400) \\
(0.00345)\end{array}$ & $\begin{array}{c}-0.00243 * * * \\
(0.000358) \\
(0.00436)\end{array}$ \\
\hline$E w m a_{j, t}$ & & & $\begin{array}{c}0.0527 \\
(0.0694)\end{array}$ & $\begin{array}{c}0.0593 \\
(0.0737)\end{array}$ & $\begin{array}{l}0.231 * \\
(0.135)\end{array}$ \\
\hline Estatal & & & $\begin{array}{c}0.00184 \\
(0.00317)\end{array}$ & $\begin{array}{l}-0.000515 \\
(0.00337)\end{array}$ & \\
\hline emissão-476 & & & $\begin{array}{l}-0.00290 \\
(0.00443)\end{array}$ & $\begin{array}{l}-0.00494 \\
(0.00415)\end{array}$ & \\
\hline Constant & $\begin{array}{l}-0.00155 \\
(0.00172)\end{array}$ & $\begin{array}{c}-0.0484 * * * \\
(0.00868)\end{array}$ & $\begin{array}{c}-0.0496 * * * \\
(0.00985)\end{array}$ & $\begin{array}{c}-0.0573 * * * \\
(0.0127)\end{array}$ & $\begin{array}{c}-0.0991 * * * \\
(0.0180)\end{array}$ \\
\hline Efeito Fixo & Não & Não & Não & Não & Sim \\
\hline Controles de liquidez & Não & Não & Não & Sim & Sim \\
\hline Observações & 1,302 & 1,302 & 1,231 & 1,231 & 1,231 \\
\hline $\mathrm{R}$-squared & 0.422 & 0.448 & 0.502 & 0.506 & 0.532 \\
\hline
\end{tabular}

Outra análise é relacionada à variável ligada a volatilidade da ação o $E w m a_{j, t}$, seu coeficiente é positivo e significante, resultado em linha com o estudo de Campbell e Taksler (2003), em que a volatilidade da ação tem um papel importante para explicar mudanças no yield das debêntures. A intuição é que quanto maior a volatilidade da ação da empresa, maior seu risco de default, elevando o prêmio das debêntures. Já as variáveis que medem volatilidade do mercado de forma agregada também são significativas porém negativas. É provável que uma maior volatilidade do mercado acionário leve os investidores para mercado de títulos corporativos, que possuem menor risco. Um aumento da demanda por esses títulos diminui a sua taxa de juros. 
As variáveis liquidez não afetam de forma significativa os coeficientes das outras variáveis e seus valores são apresentados na (tabela 9) do anexo.

Tabela 7: Regressões empilhadas - variável dependente: variação do yield da debênture (2018). A tabela apresenta os coeficientes estimados de especificações alternativas da equação (4.1). Na coluna 1 usa-se a variação do yield do título público, além dos retornos defasado, contemporâneo e futuro da ação $\left(R_{j, t-1}, R_{j, t}, R_{j, t+1}\right)$. Na coluna 2 adiciona-se variáveis de mercado: retorno corrente do Ibovespa $\left(\operatorname{Rbov}_{t}\right)$ e índices de volatilidade $\left(\right.$ Vix $\left._{t}, V_{o l b r}\right)$. Na coluna 3 considera-se adiciona-se dummies de firma (Estatal e emissão 476), além de um EWMA para a ação. $\mathrm{Na}$ coluna 4 considera-se efeitos de liquidez e na última coluna insere-se efeito fixo para cada firma, omitindo as dummies.

\begin{tabular}{|c|c|c|c|c|c|}
\hline Variáveis & $\begin{array}{c}1) \\
\text { Base } \\
\end{array}$ & $\begin{array}{c}\text { (2) } \\
\text { Mercado }\end{array}$ & $\begin{array}{c}(3) \\
\text { Mercado-empresa }\end{array}$ & $\begin{array}{c}\text { (4) } \\
\text { Liquidez }\end{array}$ & $\begin{array}{l}(5) \\
\mathrm{EF}\end{array}$ \\
\hline$\Delta T_{i, t}$ & $\begin{array}{c}0.443 * * * \\
(0.113)\end{array}$ & $\begin{array}{c}0.335 * * * \\
(0.105)\end{array}$ & $\begin{array}{c}0.327 * * * \\
(0.103)\end{array}$ & $\begin{array}{c}0.334 * * * \\
(0.102)\end{array}$ & $\begin{array}{c}0.374 * * * \\
(0.101)\end{array}$ \\
\hline$R_{j, t+1}$ & $\begin{array}{l}-0.0153 \\
(0.0275)\end{array}$ & $\begin{array}{l}-0.00456 \\
(0.0268)\end{array}$ & $\begin{array}{l}0.00987 \\
(0.0220)\end{array}$ & $\begin{array}{l}0.00353 \\
(0.0223)\end{array}$ & $\begin{array}{l}-0.00344 \\
(0.0226)\end{array}$ \\
\hline$R_{j, t}$ & $\begin{array}{c}-0.215 * * * \\
(0.0746)\end{array}$ & $\begin{array}{c}-0.0892 * * * \\
(0.0341)\end{array}$ & $\begin{array}{c}-0.0633 * * \\
(0.0306)\end{array}$ & $\begin{array}{c}-0.0701 * * \\
(0.0295)\end{array}$ & $\begin{array}{c}-0.0952 * * * \\
(0.0355)\end{array}$ \\
\hline$R_{j, t-1}$ & $\begin{array}{c}0.0293 \\
(0.0466)\end{array}$ & $\begin{array}{c}0.0481 \\
(0.0451)\end{array}$ & $\begin{array}{c}0.0535 \\
(0.0511)\end{array}$ & $\begin{array}{c}0.0293 \\
(0.0399)\end{array}$ & $\begin{array}{l}-0.0156 \\
(0.0446)\end{array}$ \\
\hline $\operatorname{Rbov}_{t}$ & & $\begin{array}{c}-0.446 * * * \\
(0.107)\end{array}$ & $\begin{array}{c}-0.469 * * * \\
(0.105)\end{array}$ & $\begin{array}{c}-0.472 * * * \\
(0.104)\end{array}$ & $\begin{array}{c}-0.424 * * * \\
(0.102)\end{array}$ \\
\hline$V i x_{t}$ & & $\begin{array}{l}-0.00227^{*} \\
(0.00119)\end{array}$ & $\begin{array}{c}-0.00258 * * \\
(0.00104)\end{array}$ & $\begin{array}{c}-0.00286 * * * \\
(0.000957)\end{array}$ & $\begin{array}{c}-0.00301 * * * \\
(0.000976)\end{array}$ \\
\hline Volbr $_{t}$ & & $\begin{array}{c}-0.00181 * * * \\
(0.000667)\end{array}$ & $\begin{array}{c}-0.00195 * * * \\
(0.000713)\end{array}$ & $\begin{array}{l}-0.00165 * * \\
(0.000644)\end{array}$ & $\begin{array}{l}-0.00170 \\
(0.00112)\end{array}$ \\
\hline$E w m a_{j, t}$ & & & $\begin{array}{l}0.382^{*} \\
(0.218)\end{array}$ & $\begin{array}{c}0.488 * * * \\
(0.0788)\end{array}$ & $\begin{array}{c}9.079 * * * \\
(3.371)\end{array}$ \\
\hline Estatal & & & $\begin{array}{c}0.00436 \\
(0.00401)\end{array}$ & $\begin{array}{l}0.00686^{*} \\
(0.00364)\end{array}$ & \\
\hline emissão-476 & & & $\begin{array}{l}-0.00311 \\
(0.00373)\end{array}$ & $\begin{array}{l}-0.00236 \\
(0.00382)\end{array}$ & \\
\hline Constant & $\begin{array}{c}-0.00533 * * * \\
(0.00172)\end{array}$ & $\begin{array}{c}0.0816^{* * * *} \\
(0.0280)\end{array}$ & $\begin{array}{c}0.0827 * * * \\
(0.0279)\end{array}$ & $\begin{array}{c}0.127 * * * \\
(0.0336)\end{array}$ & $\begin{array}{c}0.0708 \\
(0.0864)\end{array}$ \\
\hline Efeito Fixo & Não & Não & Não & Não & Sim \\
\hline Controles de liquidez & Não & Não & Não & Sim & Sim \\
\hline Observações & 558 & 558 & 540 & 540 & 540 \\
\hline R-squared & 0.512 & 0.591 & 0.602 & 0.640 & 0.669 \\
\hline
\end{tabular}

Desvio padrão em parênteses

$* * * \mathrm{p}<0.01, * * \mathrm{p}<0.05, * \mathrm{p}<0.1$ 


\subsection{Regressões Nível}

Nesta subseção explora-se os resultados da estimação da regressão da equação (4.3). O objetivo é entender como parte dos controles utilizados no modelo principal explicam apenas o nível do yield das debêntures e não a sua variação. Utiliza-se como variáveis dependentes: o yield do título público, a liquidez de Amihud, o número de dias sem negócio e o spread de compra e venda, além das dummies de emissão da Instrução $\mathrm{n}^{\circ} 476$ e de empresas estatais totalizando 1.946 observações. Na primeira coluna da tabela abaixo tem-se o modelo básico; na coluna seguinte estão as estimativas das mesmas variáveis agora computando os erros padrão segundo Newey e West (1986); e, por fim, na terceira coluna inclui-se o efeito fixo para cada papel.

Tabela 8: Regressões empilhadas - variável dependente: yield da debênture (2012 a 2018). A coluna 1 apresenta os coeficientes estimados da equação (4.3). Como variáveis independentes considera-se o yield do título público $\left(T_{i, j}\right)$, dummies de empresa estatal (Estatal) e empresas que emitem títulos via instrução 476 (emissão 476); medida de liquidez de Amihud (iliquit_amihud), o número de dias que a debênture passa sem ser negociada (dias_sem_ negócios), o spread da debênture e o prazo médio em que o detentor da debênture recupera seu investimento (Duration). Na segunda coluna apresenta-se a estimativa dos erros padrão segundo Newey e West (1986). Na coluna três inclui-se um efeito fixo para cada debênture e omite-se as dummies.

\begin{tabular}{|c|c|c|c|}
\hline Variáveis & $\begin{array}{c}(1) \\
\text { Base }\end{array}$ & $\begin{array}{c}(2) \\
\text { Newey-West }\end{array}$ & $\begin{array}{l}\text { (3) } \\
\mathrm{EF}\end{array}$ \\
\hline$T_{i, j}$ & $\begin{array}{c}0.790^{* * * *} \\
(0.0319)\end{array}$ & $\begin{array}{c}0.790 * * * \\
(0.0675)\end{array}$ & $\begin{array}{c}0.858 * * * \\
(0.0640)\end{array}$ \\
\hline Estatal & $\begin{array}{c}0.263 * * * \\
(0.0543)\end{array}$ & $\begin{array}{c}0.263^{* * *} \\
(0.123)\end{array}$ & \\
\hline emissão_476 & $\begin{array}{c}0.116 \\
(0.0717)\end{array}$ & $\begin{array}{c}0.116 \\
(0.160)\end{array}$ & \\
\hline iliqui_amihud & $\begin{array}{c}-16,748 * * * \\
(4,582)\end{array}$ & $\begin{array}{c}-16,748^{* * *} \\
(5,040)\end{array}$ & $\begin{array}{c}-3,834^{*} \\
(2,034)\end{array}$ \\
\hline dias_sem_negócios & $\begin{array}{c}0.0508 * * * \\
(0.00388)\end{array}$ & $\begin{array}{c}0.0508 * * * \\
(0.00633)\end{array}$ & $\begin{array}{c}0.00266 \\
(0.00799)\end{array}$ \\
\hline spread & $\begin{array}{c}1.356^{* *} \\
(0.613)\end{array}$ & $\begin{array}{c}1.356 * * * \\
(0.323)\end{array}$ & $\begin{array}{l}0.601 * \\
(0.312)\end{array}$ \\
\hline Duration & $\begin{array}{c}-0.000413 * * * \\
(9.83 \mathrm{e}-05)\end{array}$ & $\begin{array}{c}-0.000413 * * \\
(0.000179)\end{array}$ & $\begin{array}{c}0.000339 \\
(0.000264)\end{array}$ \\
\hline Constant & $\begin{array}{l}0.648^{*} \\
(0.360)\end{array}$ & $\begin{array}{c}0.648 \\
(0.441)\end{array}$ & $\begin{array}{c}0.999 * * \\
(0.420)\end{array}$ \\
\hline Observações & 1,922 & 1,922 & 1,922 \\
\hline R-squared & 0.510 & & 0.723 \\
\hline
\end{tabular}

Os resultados apresentados nas duas primeiras colunas são bastante similares. Empresas estatais, em média, têm yields 0,263 vezes maiores que as empresas com capital majoritariamente privado. A liquidez de Amihud mede a sensibilidade do preço de um ativo em relação ao volume negociado: quanto maior for esta medida, mais líquido é o papel; portanto, seu coeficiente negativo sugere que há um prêmio de liquidez. A variável de dias sem negócio é significante 
e positiva: quanto mais dias sem negócio, menos líquido é o papel, o que faz com que investidores exijam uma taxa de juros maior para carregá-lo. Conforme o esperado, a variável spread, que também é uma medida de liquidez, é significante e positiva. Neste caso, quanto maior for a diferença entre a taxa de compra e a taxa de venda, menor será a liquidez do papel.

É interessante observar que, ao incluir o efeito fixo de papel, as variáveis de dias sem negócio e duration deixam de ser significantes. Além disso, os coeficientes da liquidez de Amihud e do spread diminuem consideravelmente, sugerindo que papéis que há papéis que são pouco líquidos da sua emissão até o seu vencimento.

\subsection{Robustez}

Nos testes de robustez são incluídas as variáveis defasadas de $\Delta T_{i, j}$ e $R b o v_{t}$. O resultado é apresentado na tabela 11 do anexo. O principal interesse desta verificação é checar se o retorno defasado das ações é significativo apenas devido a um possível viés de variável omitida. Os resultados, porém, mostram que essas variáveis não são significativas e que sua inclusão não impacta na significância das variáveis previamente consideradas.

Nas tabelas 12, 13 e 14 apresenta-se uma outra especificação, usando a formulação da equação (4.2), onde a variável dependente passar a ser a variação simples do yield. Utiliza-se os mesmos controles da estimação do modelo principal e as estimações foram feitas com (I) a amostra completa, (II) com ela particionada de 2012 a 2017 e (III) apenas com os dados de 2018. Os principais resultados se mantêm e a relação entre debêntures e as outras variáveis permanece. A variação dos títulos públicos continua positivamente correlacionada com a variação das debêntures. Similarmente, o retorno defasado das ações continua sendo significativo durante o período de 2012 a 2017 e deixa de ser significativo no período de 2018. Por fim, o retorno contemporâneo passa a ser significativo quando se considera a subamostra de 2018. Como afirmado anteriormente, esses três importantes resultados são persistentes em todas as especificações consideradas, independentemente da inclusão de mais controles.

Na tabela 15 apresenta-se os resultados das estimações com os dados na frequência semanal. A variação do título público e as variáveis de mercado, como o retorno da Ibovespa, são significantes a 1\%. Já os retornos defasado e contemporâneo da ação não são significativos, sugerindo que a relação entre ações e debêntures acontece principalmente em um intervalo de tempo maior. 



\section{Conclusão}

Este trabalho analisa a evolução do mercado secundário de debêntures brasileiro e como ele se relaciona com os mercados de títulos públicos e acionário. Para tanto foi construída uma base a partir de todas as negociações de debêntures atreladas à inflação entre 2012 e 2018, cruzando estes dados com a ação mais líquida de cada empresa e com os títulos públicos de igual vencimento.

Os resultados encontrados mostram que o principal fator que explica a variação do yield das debêntures é a variação da taxa de juros do título público. Este resultado é persistente para todas as especificações alternativas do modelo considerado e vai na mesma linha dos demais trabalhos desta literatura. Um segundo importante achado é a relação encontrada entre a variação do yield e o mercado acionário. Num primeiro momento, que vai desde 2012 até 2017, vê-se que o retorno mensal defasado da ação é significante para explicar a variação da debênture. Este resultado se mantém mesmo com a inclusão do retorno agregado do mercado acionário e com a inclusão de outras variáveis defasadas, sugerindo que existe um fluxo de informação entre os dois mercados. A partir de 2018, é possível verificar que, com o aumento do número de negócios, esta dinâmica muda: o retorno defasado da ação deixa de ter poder explicativo e, em seu lugar, o retorno contemporâneo passa a ser significativo. Além disso, outras variáveis de mercado tais quais o retorno do índice Bovespa e os índices de volatilidade passam a ser mais importantes para entender o comportamento do mercado secundário de debêntures, sugerindo que este está mais dinâmico, reagindo mais rapidamente a novas informações.

Pesquisas futuras podem analisar se os resultados deste trabalho se mantêm com a evolução do mercado secundário de debêntures e se a relação entre debêntures e ações continua se verificando na frequência mensal - ou se ela passa a se expressar numa frequência diferente. Outra possível extensão seria verificar a relação entre debêntures negociadas no Brasil com as corporate bonds da mesma empresa negociadas em mercados mais desenvolvidos como o norte-americano. 



\section{Apêndice}

Tabela 9

\begin{tabular}{|c|c|c|c|c|c|c|}
\hline Variáveis & $\begin{array}{c}(1) \\
2012-2018\end{array}$ & $\begin{array}{c}(2) \\
\text { EF-2012-2018 }\end{array}$ & $\begin{array}{c}(3) \\
2012-2017\end{array}$ & $\begin{array}{c}(4) \\
\text { EF-2012-2017 }\end{array}$ & $\begin{array}{c}5) \\
2018\end{array}$ & $\begin{array}{c}6) \\
\text { EF-2018 }\end{array}$ \\
\hline iliqui_amihud & $\begin{array}{c}168.2 \\
(562.1)\end{array}$ & $\begin{array}{c}1,206 * * \\
(517.9)\end{array}$ & $\begin{array}{c}2,022 \\
(1,914)\end{array}$ & $\begin{array}{c}2,112 \\
(2,058)\end{array}$ & $\begin{array}{c}845.6 \\
(593.0)\end{array}$ & $\begin{array}{c}1,639 * * \\
(672.9)\end{array}$ \\
\hline dias_sem_negócios & $\begin{array}{c}0.000393 * * * \\
(0.000145)\end{array}$ & $\begin{array}{c}0.000529 * * \\
(0.000244)\end{array}$ & $\begin{array}{c}8.75 \mathrm{e}-05 \\
(0.000185)\end{array}$ & $\begin{array}{c}0.000390 \\
(0.000303)\end{array}$ & $\begin{array}{c}0.000656 * * * \\
(0.000201)\end{array}$ & $\begin{array}{r}0.000655 \\
(0.000415)\end{array}$ \\
\hline spread & $\begin{array}{l}-0.0190 \\
(0.0142)\end{array}$ & $\begin{array}{l}-0.0252 \\
(0.0179)\end{array}$ & $\begin{array}{l}-0.00138 \\
(0.00735)\end{array}$ & $\begin{array}{l}0.00390 \\
(0.0103)\end{array}$ & $\begin{array}{c}-0.0560 * * * \\
(0.00615)\end{array}$ & $\begin{array}{c}-0.0475 * * * \\
(0.00566)\end{array}$ \\
\hline Duration & $\begin{array}{c}4.41 \mathrm{e}-06 \\
(3.40 \mathrm{e}-06)\end{array}$ & $\begin{array}{c}2.15 \mathrm{e}-05 * * * \\
(4.10 \mathrm{e}-06)\end{array}$ & $\begin{array}{c}1.03 \mathrm{e}-05 * * * \\
(3.98 \mathrm{e}-06)\end{array}$ & $\begin{array}{c}3.38 \mathrm{e}-05 * * * \\
(9.86 \mathrm{e}-06)\end{array}$ & $\begin{array}{c}-5.33 \mathrm{e}-06 \\
(5.16 \mathrm{e}-06)\end{array}$ & $\begin{array}{l}-2.70 \mathrm{e}-05 \\
(6.00 \mathrm{e}-05)\end{array}$ \\
\hline Observações & 1,838 & 1,771 & 1,283 & 1,231 & 555 & 540 \\
\hline
\end{tabular}


Tabela 10: Regressões empilhadas - variável dependente: variação do yield da debênture (2012 a 2018). Na coluna 1 usa-se a variação corrente e defasada do yield do título público, além dos retornos defasado, contemporâneo e futuro da ação $\left(R_{j, t-1}, R_{j, t}, R_{j, t+1}\right)$. Na coluna 2 adiciona-se variáveis de mercado: retornos corrente e defasado do Ibovespa $\left(\operatorname{Rbov}_{t}, \operatorname{Rbov}_{t-1}\right)$ e índices de volatilidade $\left(V_{i} x_{t}, V_{o l b r}\right)$. Na coluna 3 considera-se adiciona-se dummies de firma (Estatal e emissão 476), além de um EWMA para a ação. Na coluna 4 considera-se efeitos de liquidez e na última coluna insere-se efeito fixo para cada firma, omitindo as dummies.

\begin{tabular}{|c|c|c|c|c|c|}
\hline Variáveis & $\begin{array}{c}(1) \\
\text { Base }\end{array}$ & $\begin{array}{c}(2) \\
\text { Mercado }\end{array}$ & $\begin{array}{c}\text { (3) } \\
\text { Mercado-empresa }\end{array}$ & $\begin{array}{c}\text { (4) } \\
\text { Liquidez }\end{array}$ & $\begin{array}{l}(5) \\
\mathrm{EF}\end{array}$ \\
\hline$\Delta T_{i, j}$ & $\begin{array}{c}0.461 * * * \\
(0.0755)\end{array}$ & $\begin{array}{c}0.426 * * * \\
(0.0773)\end{array}$ & $\begin{array}{c}0.417 * * * \\
(0.0763)\end{array}$ & $\begin{array}{c}0.416 * * * \\
(0.0767)\end{array}$ & $\begin{array}{l}0.423 * * * \\
(0.0722)\end{array}$ \\
\hline$\Delta T_{i, j-1}$ & $\begin{array}{c}0.0115 \\
(0.0211)\end{array}$ & $\begin{array}{l}-0.00421 \\
(0.0231)\end{array}$ & $\begin{array}{l}-0.00739 \\
(0.0228)\end{array}$ & $\begin{array}{l}-0.00823 \\
(0.0215)\end{array}$ & $\begin{array}{l}-0.00299 \\
(0.0180)\end{array}$ \\
\hline$R_{j, t+1}$ & $\begin{array}{l}-0.00952 \\
(0.0133)\end{array}$ & $\begin{array}{l}-0.0147 \\
(0.0133)\end{array}$ & $\begin{array}{l}-0.0177 \\
(0.0132)\end{array}$ & $\begin{array}{l}-0.0152 \\
(0.0131)\end{array}$ & $\begin{array}{l}-0.00518 \\
(0.0123)\end{array}$ \\
\hline$R_{j, t}$ & $\begin{array}{l}-0.0534 * \\
(0.0304)\end{array}$ & $\begin{array}{c}-0.000988 \\
(0.0210)\end{array}$ & $\begin{array}{l}-0.00240 \\
(0.0206)\end{array}$ & $\begin{array}{l}-0.00275 \\
(0.0208)\end{array}$ & $\begin{array}{l}0.00702 \\
(0.0243)\end{array}$ \\
\hline$R_{j, t-1}$ & $\begin{array}{c}-0.0481 * * * \\
(0.0157)\end{array}$ & $\begin{array}{c}-0.0483 * * * \\
(0.0168)\end{array}$ & $\begin{array}{c}-0.0497 * * * \\
(0.0170)\end{array}$ & $\begin{array}{c}-0.0495 * * * \\
(0.0177)\end{array}$ & $\begin{array}{c}-0.0404 * * * \\
(0.0134)\end{array}$ \\
\hline $\operatorname{Rbov}_{t}$ & & $\begin{array}{c}-0.170 * * * \\
(0.0489)\end{array}$ & $\begin{array}{c}-0.182 * * * \\
(0.0473)\end{array}$ & $\begin{array}{c}-0.174 * * * \\
(0.0493)\end{array}$ & $\begin{array}{c}-0.178 * * * \\
(0.0384)\end{array}$ \\
\hline$R b o v_{t-1}$ & & $\begin{array}{l}-0.00499 \\
(0.0233)\end{array}$ & $\begin{array}{l}-0.0140 \\
(0.0252)\end{array}$ & $\begin{array}{l}-0.00729 \\
(0.0245)\end{array}$ & $\begin{array}{l}-0.00864 \\
(0.0249)\end{array}$ \\
\hline$V i x_{t}$ & & $\begin{array}{l}-0.000626 \\
(0.000433)\end{array}$ & $\begin{array}{c}-0.000865 * * \\
(0.000388)\end{array}$ & $\begin{array}{c}-0.000863 * * \\
(0.000394)\end{array}$ & $\begin{array}{l}-0.000786^{*} \\
(0.000395)\end{array}$ \\
\hline Volbr $_{t}$ & & $\begin{array}{c}-0.00115^{* * * *} \\
(0.000353)\end{array}$ & $\begin{array}{c}-0.00117 * * * \\
(0.000353)\end{array}$ & $\begin{array}{c}-0.00122 * * * \\
(0.000348)\end{array}$ & $\begin{array}{r}0.00128 * * * \\
(0.000314)\end{array}$ \\
\hline$E w m a_{j, t}$ & & & $\begin{array}{c}0.0963 \\
(0.0877)\end{array}$ & $\begin{array}{c}0.124 \\
(0.109)\end{array}$ & $\begin{array}{l}0.549^{*} \\
(0.285)\end{array}$ \\
\hline Estatal & & & $\begin{array}{c}0.00404 \\
(0.00255)\end{array}$ & $\begin{array}{c}0.00353 \\
(0.00266)\end{array}$ & \\
\hline emissão_476 & & & $\begin{array}{l}-0.00384 \\
(0.00340)\end{array}$ & $\begin{array}{l}-0.00293 \\
(0.00322)\end{array}$ & \\
\hline Constant & $\begin{array}{c}-0.00265 * * \\
(0.00133)\end{array}$ & $\begin{array}{l}-0.0185 * * \\
(0.00772)\end{array}$ & $\begin{array}{l}-0.0149 * \\
(0.00814)\end{array}$ & $\begin{array}{c}-0.0210^{*} \\
(0.0108)\end{array}$ & $\begin{array}{c}-0.0467 * * * \\
(0.0133)\end{array}$ \\
\hline $\begin{array}{l}\text { Observações } \\
\text { R-squared }\end{array}$ & 1,854 & 1,854 & 1,832 & 1,832 & $\begin{array}{l}1,854 \\
0.502\end{array}$ \\
\hline
\end{tabular}

Desvio padrão em parênteses $* * * \mathrm{p}<0.01, * * \mathrm{p}<0.05, * \mathrm{p}<0.1$ 
Tabela 11: Regressões empilhadas - variável dependente: variação simples do yield da debênture (2012 a 2018). A tabela apresenta os coeficientes estimados de especificações alternativas da equação (4.2). Na coluna 1 usase a variação simples do yield do título público, além dos retornos defasado, contemporâneo e futuro da ação $\left(R_{j, t-1}, R_{j, t}, R_{j, t+1}\right)$. Na coluna 2 adiciona-se variáveis de mercado: retorno corrente do Ibovespa $\left(R b o v_{t}\right)$ e índices de volatilidade $\left(V i x_{t}, V o l b r_{t}\right)$. Na coluna 3 considera-se adiciona-se dummies de firma (Estatal e emissão 476), além de um EWMA para a ação. Na coluna 4 considera-se efeitos de liquidez e na última coluna insere-se efeito fixo para cada firma, omitindo as dummies.

\begin{tabular}{|c|c|c|c|c|c|}
\hline Variáveis & $\begin{array}{c}(1) \\
\text { Base }\end{array}$ & $\begin{array}{c}(2) \\
\text { Mercado }\end{array}$ & $\begin{array}{c}(3) \\
\text { Mercado-empresa }\end{array}$ & $\begin{array}{c}\text { (4) } \\
\text { Liquidez }\end{array}$ & $\begin{array}{l}(5) \\
\mathrm{EF}\end{array}$ \\
\hline$D i f-T_{i, j}$ & $\begin{array}{c}0.483 * * * \\
(0.0698)\end{array}$ & $\begin{array}{c}0.459 * * * \\
(0.0700)\end{array}$ & $\begin{array}{c}0.451 * * * \\
(0.0695)\end{array}$ & $\begin{array}{c}0.450 * * * \\
(0.0694)\end{array}$ & $\begin{array}{c}0.460 * * * \\
(0.0606)\end{array}$ \\
\hline$R_{j, t+1}$ & $\begin{array}{c}-0.0751 \\
(0.103)\end{array}$ & $\begin{array}{l}-0.120 \\
(0.101)\end{array}$ & $\begin{array}{c}-0.136 \\
(0.0971)\end{array}$ & $\begin{array}{l}-0.128 \\
(0.102)\end{array}$ & $\begin{array}{l}-0.0305 \\
(0.0665)\end{array}$ \\
\hline$R_{j, t}$ & $\begin{array}{c}-0.344 * * \\
(0.156)\end{array}$ & $\begin{array}{l}-0.0284 \\
(0.128)\end{array}$ & $\begin{array}{c}-0.0471 \\
(0.124)\end{array}$ & $\begin{array}{l}-0.0609 \\
(0.135)\end{array}$ & $\begin{array}{l}0.0396 \\
(0.117)\end{array}$ \\
\hline$R_{j, t-1}$ & $\begin{array}{c}-0.404 * * * \\
(0.112)\end{array}$ & $\begin{array}{c}-0.388 * * * \\
(0.119)\end{array}$ & $\begin{array}{c}-0.419 * * * \\
(0.130)\end{array}$ & $\begin{array}{c}-0.404 * * * \\
(0.137)\end{array}$ & $\begin{array}{c}-0.331 * * * \\
(0.0946)\end{array}$ \\
\hline$R b o v_{t}$ & & $\begin{array}{c}-0.919 * * \\
(0.373)\end{array}$ & $\begin{array}{c}-0.979 * * * \\
(0.341)\end{array}$ & $\begin{array}{c}-0.875 * * \\
(0.368)\end{array}$ & $\begin{array}{c}-0.974 * * * \\
(0.268)\end{array}$ \\
\hline$V i x_{t}$ & & $\begin{array}{l}-0.000561 \\
(0.00421)\end{array}$ & $\begin{array}{l}-0.00241 \\
(0.00314)\end{array}$ & $\begin{array}{l}-0.00191 \\
(0.00286)\end{array}$ & $\begin{array}{l}-0.00137 \\
(0.00241)\end{array}$ \\
\hline Volbr $_{t}$ & & $\begin{array}{c}-0.00750 * * * \\
(0.00225)\end{array}$ & $\begin{array}{c}-0.00768 * * * \\
(0.00211)\end{array}$ & $\begin{array}{c}-0.00862 * * * \\
(0.00192)\end{array}$ & $\begin{array}{c}0.00921 * * * \\
(0.00192)\end{array}$ \\
\hline$E w m a_{j, t}$ & & & $\begin{array}{l}+0.837 \\
(0.865)\end{array}$ & $\begin{array}{l}+1.302 \\
(1.161)\end{array}$ & $\begin{array}{c}+4.023 * * \\
(1.662)\end{array}$ \\
\hline Estatal & & & $\begin{array}{c}0.0168 \\
(0.0149)\end{array}$ & $\begin{array}{l}0.00863 \\
(0.0165)\end{array}$ & \\
\hline emissão-476 & & & $\begin{array}{l}-0.0240 \\
(0.0260)\end{array}$ & $\begin{array}{l}-0.0183 \\
(0.0241)\end{array}$ & \\
\hline Constante & -0.00949 & $-0.166 * * *$ & $-0.138 * * *$ & -0.107 & $-0.280 * * *$ \\
\hline Efeito Fixo & Não & Não & Não & Não & Sim \\
\hline Controles de liquidez & Não & Não & Não & Sim & Sim \\
\hline Observações & 1,860 & 1,860 & 1,838 & 1,838 & 1,860 \\
\hline R-squared & & & & 0.470 & 0.517 \\
\hline
\end{tabular}


Tabela 12: Regressões empilhadas - variável dependente: variação simples do yield da debênture (2012 a 2017). A tabela apresenta os coeficientes estimados de especificações alternativas da equação (4.2). Na coluna 1 usase a variação simples do yield do título público, além dos retornos defasado, contemporâneo e futuro da ação $\left(R_{j, t-1}, R_{j, t}, R_{j, t+1}\right)$. Na coluna 2 adiciona-se variáveis de mercado: retorno corrente do Ibovespa $\left(R b o v_{t}\right)$ e índices de volatilidade $\left(V i x_{t}, V_{\text {olbr }}\right.$ ). Na coluna 3 considera-se adiciona-se dummies de firma (Estatal e emissão 476), além de um EWMA para a ação. Na coluna 4 considera-se efeitos de liquidez e na última coluna insere-se efeito fixo para cada firma, omitindo as dummies.

\begin{tabular}{|c|c|c|c|c|c|}
\hline Variáveis & $\begin{array}{c}(1) \\
\text { Base }\end{array}$ & $\begin{array}{c}(2) \\
\text { Mercado }\end{array}$ & $\begin{array}{c}\text { (3) } \\
\text { Mercado-empresa }\end{array}$ & $\begin{array}{c}\text { (4) } \\
\text { Liquidez }\end{array}$ & $\begin{array}{l}(5) \\
\mathrm{EF}\end{array}$ \\
\hline$D i f-T_{i, j}$ & $\begin{array}{c}0.582 * * * \\
(0.0879)\end{array}$ & $\begin{array}{c}0.563 * * * \\
(0.0878)\end{array}$ & $\begin{array}{c}0.550 * * * \\
(0.0876)\end{array}$ & $\begin{array}{c}0.545^{* * *} \\
(0.0876)\end{array}$ & $\begin{array}{c}0.556^{* * * *} \\
(0.0935)\end{array}$ \\
\hline$R_{j, t+1}$ & $\begin{array}{c}0.0302 \\
(0.0796)\end{array}$ & $\begin{array}{l}-0.0429 \\
(0.0800)\end{array}$ & $\begin{array}{l}-0.0539 \\
(0.0800)\end{array}$ & $\begin{array}{l}-0.0336 \\
(0.0825)\end{array}$ & $\begin{array}{l}-0.00299 \\
(0.0732)\end{array}$ \\
\hline$R_{j, t}$ & $\begin{array}{l}0.0779 \\
(0.148)\end{array}$ & $\begin{array}{c}0.164 \\
(0.117)\end{array}$ & $\begin{array}{c}0.128 \\
(0.114)\end{array}$ & $\begin{array}{c}0.144 \\
(0.113)\end{array}$ & $\begin{array}{c}0.173 * \\
(0.0987)\end{array}$ \\
\hline$R_{j, t-1}$ & $\begin{array}{c}-0.467 * * * \\
(0.144)\end{array}$ & $\begin{array}{c}-0.467 * * * \\
(0.148)\end{array}$ & $\begin{array}{c}-0.487 * * * \\
(0.174)\end{array}$ & $\begin{array}{c}-0.454 * * \\
(0.178)\end{array}$ & $\begin{array}{c}-0.391 * * * \\
(0.141)\end{array}$ \\
\hline $\operatorname{Rbov}_{t}$ & & $\begin{array}{l}-0.174 \\
(0.294)\end{array}$ & $\begin{array}{l}-0.197 \\
(0.271)\end{array}$ & $\begin{array}{l}-0.153 \\
(0.255)\end{array}$ & $\begin{array}{l}-0.210 \\
(0.236)\end{array}$ \\
\hline$V i x_{t}$ & & $\begin{array}{l}-0.00287 \\
(0.00265)\end{array}$ & $\begin{array}{l}-0.00410 \\
(0.00300)\end{array}$ & $\begin{array}{l}-0.00353 \\
(0.00289)\end{array}$ & $\begin{array}{l}-0.00187 \\
(0.00252)\end{array}$ \\
\hline Volbr $_{t}$ & & $\begin{array}{r}0.0148 * * * \\
(0.00217)\end{array}$ & $\begin{array}{l}0.0152 * * * \\
(0.00228)\end{array}$ & $\begin{array}{r}0.0152 * * * \\
(0.00232)\end{array}$ & $\begin{array}{r}0.0145^{* * * *} \\
(0.00199)\end{array}$ \\
\hline$E w m a_{j, t}$ & & & $\begin{array}{c}0.339 \\
(0.543)\end{array}$ & $\begin{array}{c}0.431 \\
(0.569)\end{array}$ & $\begin{array}{c}1.695 \\
(1.099)\end{array}$ \\
\hline Estatal & & & $\begin{array}{c}0.0139 \\
(0.0204)\end{array}$ & $\begin{array}{c}-0.000368 \\
(0.0203)\end{array}$ & \\
\hline Constant & $\begin{array}{l}-0.00653 \\
(0.0110) \\
\end{array}$ & $\begin{array}{c}-0.304 * * * \\
(0.0537) \\
\end{array}$ & $\begin{array}{c}-0.285^{* * *} * \\
(0.0596)\end{array}$ & $\begin{array}{c}-0.326 * * * \\
(0.0727) \\
\end{array}$ & $\begin{array}{c}-0.608 * * * \\
(0.109)\end{array}$ \\
\hline Efeito Fixo & Não & Não & Não & Não & Sim \\
\hline Controles de liquidez & Não & Não & Não & Sim & Sim \\
\hline $\begin{array}{l}\text { Observações } \\
\text { R-squared }\end{array}$ & 1,860 & 1,860 & 1,838 & 1,838 & $\begin{array}{l}1,860 \\
0,481\end{array}$ \\
\hline
\end{tabular}

Desvio padrão em parênteses

$$
* * * \mathrm{p}<0.01, * * \mathrm{p}<0.05, * \mathrm{p}<0.1
$$


Tabela 13: Regressões empilhadas - variável dependente: variação simples do yield da debênture (2018). A tabela apresenta os coeficientes estimados de especificações alternativas da equação (4.2). Na coluna 1 usa-se a variação simples do yield do título público, além dos retornos defasado, contemporâneo e futuro da ação $\left(R_{j, t-1}, R_{j, t}, R_{j, t+1}\right)$. Na coluna 2 adiciona-se variáveis de mercado: retorno corrente do Ibovespa $\left(R b o v_{t}\right)$ e índices de volatilidade $\left(V i x_{t}, V o l b r_{t}\right)$. Na coluna 3 considera-se adiciona-se dummies de firma (Estatal e emissão 476), além de um EWMA para a ação. Na coluna 4 considera-se efeitos de liquidez e na última coluna insere-se efeito fixo para cada firma, omitindo as dummies.

\begin{tabular}{|c|c|c|c|c|c|}
\hline Variáveis & $\begin{array}{l}(1) \\
\text { Base }\end{array}$ & $\begin{array}{c}(2) \\
\text { Mercado }\end{array}$ & $\begin{array}{c}\text { (3) } \\
\text { Mercado-empresa }\end{array}$ & $\begin{array}{c}(4) \\
\text { Liquidez }\end{array}$ & $\begin{array}{l}(5) \\
\mathrm{EF}\end{array}$ \\
\hline$D i f-T_{i, j}$ & $\begin{array}{l}0.405 * * * \\
(0.0931)\end{array}$ & $\begin{array}{c}0.360 * * * \\
(0.0905)\end{array}$ & $\begin{array}{l}0.355^{* * *} * \\
(0.0901)\end{array}$ & $\begin{array}{c}0.355^{* * *} * \\
(0.0847)\end{array}$ & $\begin{array}{c}0.353 * * * \\
(0.0839)\end{array}$ \\
\hline$R_{j, t+1}$ & $\begin{array}{l}-0.182 \\
(0.265)\end{array}$ & $\begin{array}{l}-0.142 \\
(0.233)\end{array}$ & $\begin{array}{c}0.139 \\
(0.156)\end{array}$ & $\begin{array}{l}0.0146 \\
(0.105)\end{array}$ & $\begin{array}{l}0.0284 \\
(0.133)\end{array}$ \\
\hline$R_{j, t}$ & $\begin{array}{c}-1.315^{* * *} \\
(0.234)\end{array}$ & $\begin{array}{c}-0.580 * * \\
(0.283)\end{array}$ & $\begin{array}{l}-0.217 \\
(0.182)\end{array}$ & $\begin{array}{c}-0.352 * * \\
(0.138)\end{array}$ & $\begin{array}{c}-0.421^{* *} \\
(0.165)\end{array}$ \\
\hline$R_{j, t-1}$ & $\begin{array}{l}0.0709 \\
(0.326)\end{array}$ & $\begin{array}{c}0.156 \\
(0.265)\end{array}$ & $\begin{array}{c}0.276 \\
(0.385)\end{array}$ & $\begin{array}{r}-0.0604 \\
(0.179)\end{array}$ & $\begin{array}{r}-0.0574 \\
(0.234)\end{array}$ \\
\hline $\operatorname{Rbov}_{t}$ & & $\begin{array}{l}-2.360 * * * \\
(0.546)\end{array}$ & $\begin{array}{l}-2.570 * * * \\
(0.482)\end{array}$ & $\begin{array}{c}-2.678 * * * \\
(0.445)\end{array}$ & $\begin{array}{c}-2.675 * * * \\
(0.460)\end{array}$ \\
\hline$V i x_{t}$ & & $\begin{array}{l}-0.00483 \\
(0.0102)\end{array}$ & $\begin{array}{l}-0.00920 \\
(0.00642)\end{array}$ & $\begin{array}{c}-0.0137 * * * \\
(0.00373)\end{array}$ & $\begin{array}{c}-0.0146 * * * \\
(0.00355)\end{array}$ \\
\hline Volbr $_{t}$ & & $\begin{array}{c}-0.0103 * * * \\
(0.00286)\end{array}$ & $\begin{array}{l}-0.0123 * * * \\
(0.00388)\end{array}$ & $\begin{array}{c}-0.00998 * * * \\
(0.00305)\end{array}$ & $\begin{array}{l}-0.0142 * * \\
(0.00548)\end{array}$ \\
\hline$E_{w m a} a_{j, t}$ & & & $\begin{array}{l}6.081 * * \\
(2.511)\end{array}$ & $\begin{array}{c}7.501 * * * \\
(0.778)\end{array}$ & $\begin{array}{c}38.49 * * * \\
(10.20)\end{array}$ \\
\hline Estatal & & & $\begin{array}{l}-0.0150 \\
(0.0225)\end{array}$ & $\begin{array}{l}-0.0109 \\
(0.0191)\end{array}$ & \\
\hline emissão-476 & & & $\begin{array}{l}-0.00592 \\
(0.0177)\end{array}$ & $\begin{array}{l}-0.0154 \\
(0.0254)\end{array}$ & \\
\hline Constant & $\begin{array}{l}(0.144) \\
-0.0155 \\
(0.0122) \\
\end{array}$ & $\begin{array}{c}(0.148) \\
0.327 * * \\
(0.166) \\
\end{array}$ & $\begin{array}{c}(0.174) \\
0.394 * * * \\
(0.118)\end{array}$ & $\begin{array}{c}(0.178) \\
0.693 * * * \\
(0.129)\end{array}$ & $\begin{array}{c}(0.141) \\
1.000 * * \\
(0.479) \\
\end{array}$ \\
\hline Efeito Fixo & Não & Não & Não & Não & Sim \\
\hline Controles de liquidez & Não & Não & Não & Sim & Sim \\
\hline $\begin{array}{l}\text { Observações } \\
\text { R-squared }\end{array}$ & 570 & 570 & 567 & 567 & $\begin{array}{c}570 \\
0.689\end{array}$ \\
\hline
\end{tabular}


Tabela 14: Regressões empilhadas - variável dependente: variação do yield da debênture (2012 a 2018). A tabela apresenta os coeficientes estimados de especificações alternativas da equação (4.2) usando dados na frequência semanal. Na coluna 1 usa-se a variação simples do yield do título público, além dos retornos defasado, contemporâneo e futuro da ação $\left(R_{j, t-1}, R_{j, t}, R_{j, t+1}\right)$. Na coluna 2 adiciona-se variáveis de mercado: retorno corrente do Ibovespa $\left(R b o v_{t}\right)$ e índices de volatilidade $\left(V i x_{t}, V o l b r_{t}\right)$. Na coluna 3 considera-se adiciona-se dummies de firma (Estatal e emissão 476), além de um EWMA para a ação. Na coluna 4 considera-se efeitos de liquidez e na última coluna insere-se efeito fixo para cada firma, omitindo as dummies.

\begin{tabular}{|c|c|c|c|c|c|}
\hline Variáveis & $\begin{array}{c}(1) \\
\text { Base }\end{array}$ & $\begin{array}{c}(2) \\
\text { Mercado }\end{array}$ & $\begin{array}{c}\text { (3) } \\
\text { Mercado-empresa }\end{array}$ & $\begin{array}{c}\text { (4) } \\
\text { Liquidez }\end{array}$ & $\begin{array}{l}(5) \\
\mathrm{EF}\end{array}$ \\
\hline$D i f-T_{i, j}$ & $\begin{array}{c}0.358 * * * \\
(0.0627)\end{array}$ & $\begin{array}{c}0.336 * * * \\
(0.0614)\end{array}$ & $\begin{array}{c}0.330 * * * \\
(0.0609)\end{array}$ & $\begin{array}{c}0.329 * * * \\
(0.0609)\end{array}$ & $\begin{array}{c}0.334 * * * \\
(0.0557)\end{array}$ \\
\hline$R_{j, t+1}$ & $\begin{array}{l}-0.00887 \\
(0.00924)\end{array}$ & $\begin{array}{l}-0.00887 \\
(0.00905)\end{array}$ & $\begin{array}{c}-0.0108 \\
(0.00946)\end{array}$ & $\begin{array}{c}-0.0105 \\
(0.00952)\end{array}$ & $\begin{array}{l}-0.00702 \\
(0.00752)\end{array}$ \\
\hline$R_{j, t}$ & $\begin{array}{c}-0.0536 * * \\
(0.0217)\end{array}$ & $\begin{array}{l}0.00388 \\
(0.0163)\end{array}$ & $\begin{array}{l}0.00371 \\
(0.0160)\end{array}$ & $\begin{array}{l}0.00396 \\
(0.0159)\end{array}$ & $\begin{array}{l}0.00762 \\
(0.0196)\end{array}$ \\
\hline$R_{j, t-1}$ & $\begin{array}{c}-0.0120 \\
(0.00773)\end{array}$ & $\begin{array}{l}-0.00665 \\
(0.00755)\end{array}$ & $\begin{array}{l}-0.00867 \\
(0.00722)\end{array}$ & $\begin{array}{l}-0.00837 \\
(0.00723)\end{array}$ & $\begin{array}{l}-0.00261 \\
(0.00999)\end{array}$ \\
\hline $\operatorname{Rbov}_{t}$ & & $\begin{array}{c}-0.210 * * * \\
(0.0448)\end{array}$ & $\begin{array}{c}-0.216 * * * \\
(0.0436)\end{array}$ & $\begin{array}{c}-0.217 * * * \\
(0.0443)\end{array}$ & $\begin{array}{c}-0.217 * * * \\
(0.0398)\end{array}$ \\
\hline$V i x_{t}$ & & $\begin{array}{c}-0.000531 * * * \\
(0.000121)\end{array}$ & $\begin{array}{c}-0.000590 * * * \\
(0.000114)\end{array}$ & $\begin{array}{c}-0.000600 * * * \\
(0.000116)\end{array}$ & $\begin{array}{c}-0.000562 * * * \\
(0.000104)\end{array}$ \\
\hline Volbr $_{t}$ & & $\begin{array}{c}-0.000697 * * * \\
(9.91 \mathrm{e}-05)\end{array}$ & $\begin{array}{c}-0.000692 * * * \\
(9.93 \mathrm{e}-05)\end{array}$ & $\begin{array}{c}-0.000679 * * * \\
(9.95 \mathrm{e}-05)\end{array}$ & $\begin{array}{c}-0.000688 * * * \\
(0.000106)\end{array}$ \\
\hline$E w m a_{j, t}$ & & & $\begin{array}{c}0.0617 \\
(0.0551)\end{array}$ & $\begin{array}{c}0.0589 \\
(0.0601)\end{array}$ & $\begin{array}{c}0.128 \\
(0.131)\end{array}$ \\
\hline $\begin{array}{l}\text { Estatal } \\
\text { emissão-476 }\end{array}$ & & & $\begin{array}{c}0.00106 \\
(0.000850) \\
-0.00105 \\
(0.00144)\end{array}$ & $\begin{array}{c}0.000990 \\
(0.000887) \\
-0.000937 \\
(0.00140)\end{array}$ & \\
\hline Constant & $\begin{array}{c}-0.00132 * * * \\
(0.000437)\end{array}$ & $\begin{array}{c}-0.00907 * * * \\
(0.00261)\end{array}$ & $\begin{array}{c}-0.00789 * * * \\
(0.00269)\end{array}$ & $\begin{array}{l}-0.0114 * * * \\
(0.00370)\end{array}$ & $\begin{array}{c}-0.0174 * * * \\
(0.00460)\end{array}$ \\
\hline Efeito Fixo & Não & Não & Não & Não & Sim \\
\hline Controles de liquidez & Não & Não & Não & Sim & Sim \\
\hline Observações & 6,069 & 6,069 & 6,029 & 6,028 & 6,068 \\
\hline R-squared & & $\begin{array}{l}\text { Desvio padrãc } \\
* * \mathrm{p}<0.01, * *\end{array}$ & $\begin{array}{l}0.05, * \mathrm{p}<0.1 \\
0.05 \text {, }{ }^{*} \text { teses }\end{array}$ & & 0.424 \\
\hline
\end{tabular}


Tabela 15: Lista maior acionista

\begin{tabular}{|c|c|c|}
\hline Empresa & Maior acionista & Estatal \\
\hline Alupar & Guarupart Participacoes Ltda. & 0 \\
\hline BR Malls Par & Canada Pension Plan Investment Board & 0 \\
\hline BR Propert & GP Capital Partners VI, L.P & 0 \\
\hline CCR SA & Andrade Gutierrez Concessoes S.A. & 0 \\
\hline Cemar & Equatorial Energia S/A & 0 \\
\hline Celpe & Neoenergia S/A & 0 \\
\hline Celpa & Equatorial Energia S/A & 0 \\
\hline Copasa & Estado de Minas Gerais & 1 \\
\hline Cosern & Neoenergia S/A & 0 \\
\hline Tran Paulist & Isa Capital do Brasil S.A & 0 \\
\hline Engie Brasil & Engie Brasil Participacoes Ltda. & 0 \\
\hline Energias BR & $\begin{array}{l}\text { Energias de Portugal Investments And } \\
\text { Services Sociedad Ltda }\end{array}$ & 0 \\
\hline Energisa & Gipar S/A & 0 \\
\hline CPFL Renovav & CPFL Geracao de Energia S/A & 0 \\
\hline Comgas & cosan & 0 \\
\hline Ger Paranap & Rio Paranapanema Participacoes S.A & 0 \\
\hline Iguatemi & Jereissati Participacoes S/A & 0 \\
\hline JSL & Simpar S.A. & 0 \\
\hline Lojas Americ & S-Velame Adm. de Rec. e Part. S/A & 0 \\
\hline Lojas Renner & $\begin{array}{l}\text { Trowe Price Associates, Inc (Gestor/Administrador - Vide Item } \\
\text { 15.7 Abaixo) }\end{array}$ & 0 \\
\hline Mills & Snow Petrel S.L. & 0 \\
\hline Mrs Logist & Mineracoes Brasileiras Reunidas S.A. & 0 \\
\hline MRV & Rubens Menin Teixeira de Souza & 0 \\
\hline Petrobras & Uniao Federal (Tesouro Nacional) & 1 \\
\hline Sabesp & Governo do Estado de Sao Paulo & 1 \\
\hline Sierrabrasil & Sierra Brazil 1 B.V. & 0 \\
\hline Sul America & Sulasapar Participacoes S/A & 0 \\
\hline Taesa & Cemig - Cia Energetica de MG & 1 \\
\hline AES Tiete E & Bndespar - BNDES Participacoes SA & 1 \\
\hline Vale & Litel Participacoes S/A & 1 \\
\hline
\end{tabular}





\section{Referências}

ASTORINO, E. S. et al. Variance premium and implied volatility in a low-liquidity option market. Revista Brasileira de Economia, SciELO Brasil, v. 71, n. 1, p. 3-28, 2017. Citado 2 vezes nas páginas 17 e 19.

CAMPBELL, J. Y. Stock returns and the term structure. Journal of financial economics, Elsevier, v. 18, n. 2, p. 373-399, 1987. Citado na página 13.

CAMPBELL, J. Y.; AMMER, J. What moves the stock and bond markets? a variance decomposition for long-term asset returns. The journal of finance, Wiley Online Library, v. 48, n. 1, p. 3-37, 1993. Citado na página 13.

CAMPBELL, J. Y.; TAKSLER, G. B. Equity volatility and corporate bond yields. The Journal of Finance, Wiley Online Library, v. 58, n. 6, p. 2321-2350, 2003. Citado 2 vezes nas páginas 23 e 26.

CAO, N.; GALVANI, V.; GUBELLINI, S. Firm-specific stock and bond predictability: New evidence from canada. International Review of Economics \& Finance, Elsevier, v. 51, p. 174-192, 2017. Citado 2 vezes nas páginas 14 e 21.

CARVALHO, F. T. M. Antonio Gledson de. The microstructure of the brazilian market for corporate bonds. Working paper, 2019. Citado na página 15.

ELTON, E. et al. Explaining the rate spread on corporate bonds", the journal of finance, vol. lvi, no. 1, february. 2001. Citado na página 13.

FAMA, E. F.; FRENCH, K. R. Common risk factors in the returns on stocks and bonds. Journal of financial economics, Elsevier, v. 33, n. 1, p. 3-56, 1993. Citado na página 13.

GONÇALVES, P. E.; SHENG, H. H. O apreçamento do spread de liquidez no mercado secundário de debêntures. Revista de Administração-RAUSP, Universidade de São Paulo, v. 45, n. 1, 2010. Citado 2 vezes nas páginas 14 e 23.

HORTA, G. T. d. L. et al. A renegociação da dívida do bndes com o tesouro nacional: antecedentes, motivação e desdobramentos. Banco Nacional de Desenvolvimento Econômico e Social, 2018. Citado na página 9.

KAWALLER, I. G.; KOCH, P. D.; KOCH, T. W. The temporal price relationship between s\&p 500 futures and the s\&p 500 index. The Journal of Finance, Wiley Online Library, v. 42, n. 5, p. 1309-1329, 1987. Citado na página 13.

KING, T.-H. D.; KHANG, K. On the importance of systematic risk factors in explaining the cross-section of corporate bond yield spreads. Journal of Banking \& Finance, Elsevier, v. 29, n. 12, p. 3141-3158, 2005. Citado na página 13.

KWAN, S. H. Firm-specific information and the correlation between individual stocks and bonds. Journal of financial economics, Elsevier, v. 40, n. 1, p. 63-80, 1996. Citado 3 vezes nas páginas 13, 14 e 21. 
LIN, H.; WANG, J.; WU, C. Liquidity risk and expected corporate bond returns. Journal of Financial Economics, Elsevier, v. 99, n. 3, p. 628-650, 2011. Citado na página 14.

MERTON, R. C. On the pricing of corporate debt: The risk structure of interest rates. The Journal of finance, Wiley Online Library, v. 29, n. 2, p. 449-470, 1974. Citado na página 13.

NEWEY, W. K.; WEST, K. D. A simple, positive semi-definite, heteroskedasticity and autocorrelationconsistent covariance matrix. [S.1.]: National Bureau of Economic Research Cambridge, Mass., USA, 1986. Citado 2 vezes nas páginas 21 e 28.

PAULA, A. L. P. d. O efeito da transparência sobre a liquidez do mercado secundário de debêntures no Brasil. Tese (Doutorado), 2016. Citado na página 14.

ROODMAN, D. Newey2: Stata module to extend newey (hac covariance estimation). Boston College Department of Economics, 2009. Citado na página 21.

SCHAEFER, S. M.; STREBULAEV, I. A. Structural models of credit risk are useful: Evidence from hedge ratios on corporate bonds. Journal of Financial Economics, Elsevier, v. 90, n. 1, p. 1-19, 2008. Citado na página 13.

SECURATO, J. R.; CARRETE, L. S.; JUNIOR, J. R. S. Precificação de títulos de dívida corporativa e seus componentes pelo modelo binomial. Revista de Administração-RAUSP, Universidade de São Paulo, v. 41, n. 1, 2006. Citado na página 14.

SHENG, H. H.; SAITO, R. Determinantes de spread das debêntures no mercado brasileiro. Revista de Administração-RAUSP, Universidade de São Paulo, v. 40, n. 2, 2005. Citado na página 14.

WHALEY, R. E. Derivatives on market volatility: Hedging tools long overdue. The journal of Derivatives, Institutional Investor Journals Umbrella, v. 1, n. 1, p. 71-84, 1993. Citado na página 19. 